\title{
WestVirginiaUniversity
}

THE RESEARCH REPOSITORY @ WVU

Graduate Theses, Dissertations, and Problem Reports

2001

\section{Home schoolers transition to public schools in West Virginia}

Anne McNeer Krout

West Virginia University

Follow this and additional works at: https://researchrepository.wvu.edu/etd

\section{Recommended Citation}

Krout, Anne McNeer, "Home schoolers transition to public schools in West Virginia" (2001). Graduate Theses, Dissertations, and Problem Reports. 2344.

https://researchrepository.wvu.edu/etd/2344

This Dissertation is protected by copyright and/or related rights. It has been brought to you by the The Research Repository @ WVU with permission from the rights-holder(s). You are free to use this Dissertation in any way that is permitted by the copyright and related rights legislation that applies to your use. For other uses you must obtain permission from the rights-holder(s) directly, unless additional rights are indicated by a Creative Commons license in the record and/ or on the work itself. This Dissertation has been accepted for inclusion in WVU Graduate Theses, Dissertations, and Problem Reports collection by an authorized administrator of The Research Repository @ WVU.

For more information, please contact researchrepository@mail.wvu.edu. 


\title{
Home Schoolers Transition to Public Schools in West Virginia
}

\author{
Anne Krout \\ Dissertation submitted to the \\ College of Human Resources and Education \\ at West Virginia University \\ in Partial fulfillment of the requirements \\ for the degree of \\ The Degree of Doctor of Education \\ in \\ Educational Leadership Studies \\ Van Dempsey, Ed. D., Co-chair \\ Phyllis Durden, Ed. D., Co-chair \\ Ernest Goeres, Ed. D. \\ Perry Phillips, Ed. D. \\ Deborah Akers, Ed. D. \\ Department of Educational Leadership Studies
}

Morgantown, West Virginia

2001

Key words: home schooling; transition; public school; dual enrollment

Copyright 2001 Anne M. Krout 


\section{Abstract \\ Home Schoolers Transition to Public Schools \\ in West Virginia}

Anne Krout

This study investigated the issues embedded in the transition of home schooled students entering or reentering public school in West Virginia. The research was primarily qualitative, however; quantitative research was also employed. Two rounds of interviews, for a total of 46 interviews, were conducted over an eight month period. The interviews included three families and their children who had been home schooled and were returning to public school. The public school teachers who had the returning students placed in their classrooms were also interviewed. The following questions guided the research: 1) What were the factors that influenced the home schooling family's decision to enter their children in public school?; 2)What do home schooling families believe public schools currently do and/or should do to support their children in their transition from home to school?; 3) What is the experience that home schooling students have upon entering public schools and what could the public schools do to participate in that experience? and 4) What are the critical issues embedded in the transition from home schooling to public schools for parents, children and educators? Major findings from the study included: 1) A key factor the in home schooling family's decision to enroll their children in public schools was to establish positive social interactions with peers and teachers; 2) Support received by the returning home schooled student from public schools, i.e., classroom teachers, is haphazard and is more apt to be academic rather than emotional support; 3) Public schools need to take an active role in the transition of returning home schooled students: 4) Conferences should be held among public school educators, home schooling parents and students before the child enters public school; 5) The development of positive social relationships by the returning student is key to the successful transition back to public school and 6) Dual enrollment in public school and home school should be considered as an option for students. 


\section{Dedication}

To my mother, Hilda Geordon McNeer, (1925-1999), the ultimate educator and student. Throughout her life she never tired of learning about the world and, in turn, graciously shared her knowledge and wisdom with family and friends. Even during her final days she continued to teach us how to live with dignity. Thank you for all you taught me. 


\section{Acknowledgements}

Everyone who completes a doctorate has "stories" to tell, many of which may fall into the "horror" genre. Because of my committee, my "stories" are filled with learning, opening doors, the sharing of knowledge and respect.

Thank you to Dr. Ernest Goeres and Dr. Perry Phillips for your friendship and support. Thank you Dr. Phyllis Durden for your example of the acceptance of the ebbs and tides of life, your interest and support. You were the "mainstay" of Cohort II. Without Dr. Van Dempsey I may have never learned the power of the "story" and qualitative research. Thank you for your thoughtful guidance and sharing your expertise. Thank you, Dr. Deborah Akers for you advice, confidentiality and friendship. You have been my mentor, not only in this endeavor, but throughout the last several years of my career.

Webster defines cohort as a group of warriors/soldiers or a companion. At times the Cohort II did unite its forces to go to "battle," although most of the time our role was that of true companions. We will forever be bound by the experience. My

gratitude and respect goes to Dr. Butch Barcus, Teddi Cox, Dr.Toni DeVore. Dr. Carl Friebel, Dr. Jeff Fry, Lyn Guy, Ron Nichols, Judy Robertson and Dr. David Stewart. Without my wonderful friends, who were my best cheerleaders, the positive outcome of this "adventure" would have been questionable. Thank you Carolyn Wysong, Shirley Bourne, Martha Draper, Sharon Dyer and Betty Thompson. 
Everyone needs a constant, a compass in their lives and for me that is my father, James McNeer. The respect he garners from his friends and daughters has been earned through a lifetime of example; therefore, his subtle pushes and gentle probes to keep me focused and reaching for the goal were so valuable and appreciated.

And finally, I thank Bill Seaver, my "best friend," my confidant and my love, who encouraged, bribed, and supported me every step of the way. Not only did he support me emotionally, but made sure that "all the little things" were in place, so that I could concentrate on the "big thing." Thank you for your unselfish, constant presence in my life.

Thank each of you for your unfailing support and encouragement. 
Table of Contents

Page

$\begin{array}{lll}\text { Abstract } & \text { ii }\end{array}$

Dedication

Acknowledgements $\quad$ iv

$\begin{array}{ll}\text { Chapter I } & 1\end{array}$

Introduction 1

Statement of Problem 2

Justification and Need of Study 2

Research Questions 3

Definition of Terms 4

Limitations $\quad 4$

Nature of Data $\quad 4$

$\begin{array}{lll}\text { Chapter II } & \text { Review of Literature } & 6\end{array}$

$\begin{array}{ll}\text { Introduction } & 6\end{array}$

$\begin{array}{ll}\text { Historical Perspective } & 7\end{array}$

Characteristics of Home Schooling Parents and Students 9

Reasons Families Choose to Home School 11

Overview of Curriculum and Materials $\quad 12$

Interactions of Home School and Public Schools 14

$\begin{array}{ll}\text { Summary of Literature } & 19\end{array}$ 
Subjects

Instruments

Design

Procedure

Personal Lens

Data Analysis

Time Schedule

Chapter IV Research Findings

The Survey

The Interviews

Introducing the Participants

Emergent Issues

$\begin{array}{lll}\text { Chapter V Researcher's Focus on Findings } & 84\end{array}$

Chapter VI Summary, Conclusions, Implications and Future Research 97

Summary

Conclusions

Research Question \#1

Research Question \#2

Research Question \#3

Research Question \#4

Dual Enrollment in Public School and Home School119

Implications 
Appendix

$\begin{array}{lll}\text { A } & 130\end{array}$

B Home Schooling Parent Survey 131

$\begin{array}{ll}\text { C Checklist for Validation } & 133\end{array}$

D Chart: Parents' Level of Education 134

$\begin{array}{lll}\text { E Chart: Parents' Occupations } & 135\end{array}$

F Summary of Responses: Why Families Home School 137

G Chart: Why Families Home School 141

H Summary of Responses: Why Home School Families

Return to Public School 142

I Chart: Why Home School Families Return to Public Schools 144

J Parent or Guardian Consent and Information Form (parent) 145

K Parent or Guardian Consent and Information Form (child) 147

L Teacher Consent and Information Form 149

M Parent Interview Guide I 151

N Parent Interview Guide II 154

$\begin{array}{lll}\text { O Student Interview Guide I } & 156\end{array}$

$\begin{array}{lll}\text { P } & \text { Student Interview Guide II } & 157\end{array}$

Q Teacher Interview Guide I $\quad 159$

$\begin{array}{lll}\text { R Teacher Interview Guide II } & 160\end{array}$ 


\section{Chapter I}

\section{Introduction}

Home schooling, as old as education itself, is an ever-increasing option for families nationwide. While precise counts are difficult to obtain, on the weekly news program Sunday Morning, the United States Department of Education was cited as estimating that ten years ago up to 350,000 students were home schooled while in the year 2000 that number has grown to be over one million. Additionally, the ranks of the students being schooled at home are growing about fifteen percent a year (Winters 2000).

Recent changes in state laws have made home instruction simpler from a legal standpoint (Lines 1987). "Several states have been forced to change previously vague statutes regarding home school instruction as a direct result of political and legal actions launched by well organized home instruction advocates, “ confirmed Roach $(1988,14)$. The number of home schooling families has grown rapidly in recent years and is likely to continue to grow.

Very few qualitative, descriptive studies have been done in the area of home schooling, and even fewer empirical works. Descriptive studies focused on parental attitudes towards public schools, characteristics, values, beliefs, achievement and practices of home schoolers, use of public libraries by home schoolers, and potential for collaborative relationships between home school families and public schools (Fash 1994; Golding 1995; Gray 1992; Hines 1994; Jessee 1993; Maness 1988; Prince 1995; VanGalen 1986). A 1995 study also targeted a legal critique of the Constitutional issues addressing home schooling families (Harbottle). 


\section{Statement of Problem}

The number of families who choose to home school their children is increasing. In West Virginia guardians/parents are required to notify the local school district of their intent to teach their children at home on a year to year basis. Many times parents decide to (re)enroll their children in public schools after home schooling for a period of time. This presents the schools, students and parents with a unique situation. The student may have scant or no records to assist the school in placement of the student in a classroom. Students are being taken from a very different learning environment into an entirely new situation. What has happened during this transition for students, families and educators in the past? In researching the transition of home schooled students into public schools, very little information was discovered. Therefore, the focus of this study will investigate the issues embedded in that transition and attempt to glean ways in which that transition can be improved for everyone involved.

The primary focus of this study will be: In what ways do home schooling families, home schooling students, and public school educators believe public schools can better interface, assist families (parents/guardians), and make the transition to public school? What are the issues that are embedded in the experience for the home schooled student and their family (parents/guardians) who choose to enter or re-enter their child(ren) into public school?

\section{Justification and Need of Study}

Public educators must now deal with the increased numbers and greater political sophistication of home schoolers. Some state governments have made unprecedented 
moves toward collaboration with parents to ensure the education of children taught at home (Roach 1988).

As the trend towards home schooling increases, educational policy makers and professional educators are called upon to respond to this phenomenon as they search for better ways to serve children who enter or reenter school from the home schooling setting. The home schooling issue therefore presents an intriguing opportunity for study. This study will attempt to provide an understanding of the nature of that experience and how schools can assist and facilitate the smooth transition from home schooling to public schools.

\section{Research Questions}

Specifically, the following questions will guide the research:

1) What are the factors that influence the home schooling family's (parents'/guardians') decision to enroll or re-enroll their child(ren) in public schools?

2) What do home schooling guardians or families, who choose to enter or re-enter their children in public schools, believe public schools currently do and/or should do to support their children in their transition from home to school?

3) What is the experience that home schooling students have upon entering or reentering public schools and what could the public schools do to participate in that experience? What is the role of the public school in that experience?

4) What are the critical issues embedded in the transition from home schooling to public schools for guardians/parent, children and educators? 


\section{Definition of Terms}

For the purpose of this study, the following definition is assigned to aid in clarity of understanding:

Home schooling: An educational alternative in which instruction is conducted in the home and community of a child or children by the parent, guardian, or other person having control of such child or children that are not classified or defined as private, denominational, or parochial formal settings.

\section{Limitations}

The following limitations were observed in this study:

1) The survey is limited to responses of home school families in one school district in West Virginia.

2) The case studies were not in-depth case studies in that the study was not extended over a long period of time.

\section{Nature of the Data}

The crux of the study was qualitative in nature, although a preliminary survey was conducted. The survey was mainly demographic in its makeup, although there were two narrative questions which sought to probe the reasons families choose to home school their children and the reasons they selected to return their children to public school.

In depth interviews were conducted with three families who choose to return their children to public school and the public school teachers who had those students in their classrooms. The interviews were conducted over a period of the school year in which the home schooled students were returned to public school. 
All the interviews were audio taped and transcribed. After all of the interviews were completed and the transcripts reviewed, there were a number of issues that emerged as key components in addressing the aforementioned research questions. The following seven issues regarding the transition were common among all those that were interviewed:

- the importance of conferences among parents, students and educators before the student returns to public school;

- the viewing of "parents as teachers" and the attitude of public teachers toward home schooling;

- the importance of the home schooled student entering public school to establish social relationships with peers and adults;

- support that is needed from the public school teachers;

- academic experiences in the transition;

- the advantages of attending public school on a part time basis for a limited transition time or as an unlimited educational choice and

- open communications between families and public schools throughout the home schooling experience.

The collection of the data and the seven emergent issues will be explained further and in Chapter VI conclusions and implications will be addressed. 


\section{Chapter II}

\section{Review of Literature}

\section{$\underline{\text { Introduction }}$}

Chapter II contains a review of the literature and research related to home schooling. Specific topics reviewed include: 1) an overview of the historical perspective; 2) characteristics of home school parents and students; 3) reasons families choose to home school their children; 4) an overview of curriculum and materials used by home schooling families; and 5) an overview of the interactions of home schooling families and public schools. The literature review includes, but is not limited to the results of Educational Resources Information Center (ERIC) search of studies and writings referring to home schooling, a search of West Virginia University and Virginia Polytechnic Institute and State University Dissertation Abstracts and search of the World Wide Web Dissertation Abstracts On-line. The information cited includes trend studies, qualitative research, and narrative summaries of experts in the field.

Throughout the literature review, no in-depth research was found targeting the transition that home schooling children and their families make when they enter or reenter public school. Golding (1995) conducted a study in Virginia in which one of the sub questions asked, "What strategies do home school families believe public schools can implement to provide a positive transition from the home school setting to the public school setting in those circumstances where home school students enter public schools?"(64). The eight families surveyed mentioned orientation (which included a review of the rules and regulations, tours of the school, and visitations to 
classes) and adaptation of instruction to the learning styles of their children. Smaller classes, shorter bus rides, stricter discipline, Bible instruction, and information on home schoolers given to public school students ahead of time were other suggestions.

\section{$\underline{\text { Historical Perspective }}$}

The phenomenon of home schooling is neither new nor unusual (Coleman 1987; Holt 1983; Lines 1987; Pitman 1987; Strout 1993). The wealthy had always been tutored at home in America and in European-based cultures. For the upper status family, the private tutor was an appendage to the family who provided instruction within the context of the household (Coleman 1987). The wealthy were not the only ones to home school their children. Other than for the elite, children were schooled via the household to learn trades and domestic skills necessary to live (Pitman 1987).

Beginning in the 14th century, boarding schools for the sons of the elite were first utilized and were supported by endowments and by tuition fees from parents. It was not until the late 19th and early 20th centuries that mass state-supported schools began (Coleman 1987). Likewise, as stated in USA Weekend, "A generation ago, home schoolers were pioneers and oddities. Now, 'almost everybody' knows one" (Sharp 1997, 4).

Thus, it is not home schooling which is new, rather that of public schooling (Coleman 1987; Pitman 1987). As Coleman observed, “...throughout the history and prehistory of the human race, mass formal schooling occupies less than a century, a period that is minuscule in the history of mankind" $(1987,32)$. Most of society's children grew up in the context of the household and the neighborhood. 
Many publicly known figures have been home schooled and include such diverse persons as writer Agatha Christie, world statesman Winston Churchill, actor Charlie Chaplin, Supreme Court Justice Sandra Day O'Connor, scientist Albert Einstein, philosopher John Stuart Mill, industrialist David Rockefeller, and anthropologist Margaret Mead (Pitman 1987). Thousands of other famous and not so famous citizens have received a home-school education.

However, in the early Seventies, only a handful of families choose to home school their children. By 1983 the number was estimated to range from 10,000 to 50,000 (Pitman 1987). As previously stated, in 1988 the United States Department of Education estimated that up to 250,000 students were home schooled (Roach 1988) and in a recent USA Today newspaper the number was estimated to be one million (Ordovensky 1996). Even though this number only represents one to two percent of the school age population (Pitman 1987), if the trend continues the present rates of growth for a generation, it is predicted that up to $10 \%$ of the families in the United States will choose to teach their own children.

In 1996, Teacher magazine reported that the number of Wisconsin home schoolers soared, continuing an annual increase of 20 percent since 1985. State figures show that the number of home schooled students reached 16,000 in just eleven years.

Whatever the number of home schooling families are now or will be in the future, this option is increasingly attractive to parents. The reasons for this phenomena include: religious beliefs and values; lack of trust that schools will keep their children safe; lack of individual time and attention given to individual students to assure learning of basic skills; over crowded classrooms; too much of the teacher's time is 
spent on discipline; and instruction is geared toward the average student, not students with special needs (Dahm 1996). Throughout the history of this country, there have always been, and continue to be parents who want to provide education for their children at home, and who believe that they have a Constitutional right to do that (Strout 1993).

\section{Characteristics of Home School Parents and Students}

A descriptive profile of the characteristic of home school parents and students might be helpful in better understanding them. The world of home schooling today is diverse with the common firm belief being that parents can and should be deeply involved in the education and the development of their own children (Lines 1987).

In a 1996 study of home school families in Idaho, Breshears indicated that:

- the mother is usually the teacher of the children,

- both parents are in the $30-40$ age group,

- $50 \%$ of the mothers do not work outside the home,

- the family has an average of three children,

- the average income is $\$ 40,000.00$,

- the parent has an average of two years of college,

- $99 \%$ of the families attend religious services on a regular basis,

- the home school child watches television an average 1.15 hours per day,

- they go to the public library on a regular basis, and

- $75 \%$ of the parents read aloud every day to their children.

Additional research indicated the following characteristics: (1) both parents are actively involved, with the mother/ homemaker as the teacher most of the time; 
(2) parents have attended or graduated from college; (3) total household income is $\$ 20,000.00$ to $\$ 30,000.00$ per year; (4) over $65 \%$ regularly attend religious services; a variety of religious backgrounds are represented; (5) three children are in the family; (6) formal instruction begins at 5.5 years of age; (7) a nearly equal number of boys and girls are educated at home; and (8) $70 \%$ of the youth are 9 to 12 years old (Ray 1988).

In 1994, research by Strange described home school parents, as sincere, committed and creative. Strange concluded:

Sincerity was apparent in their concern over curricular and instructional decisions, and in their desire to create a positive learning environment within the home. Commitment was evident in their struggle to balance the role of mother and housewife with that of teacher. Creativity was apparent in the need to provide their children with the experiences and opportunities necessary for a productive learning process, while operating within a one-income budget (abstract).

Often times public school educators voice concerns over the achievement levels and social abilities of home schooled children. However, with few exceptions, all the studies have indicated that home schooled students score as well, or better than their public school counterparts on standardized test (Hines 1993; Holt 1983; Natale 1992; Parsons 1995; Ray 1988). Home school parents have contended that they are not fearful regarding their children's social abilities. Studies have reinforced that home 
schooled children appear to be as socially adept as children who attend public schools (Parsons 1995; Lines 1987; Ray 1988).

$\underline{\text { Reasons Families Choose to Home School }}$

Parents choose home schooling for a number of reasons (Fash 1994; Gray 1992;

Holt 1983; Ray 1988; Roach 1988; Van Galen 1986). According to the Home School Legal Defense Association, the overwhelming majority of parents who choose to educate their children at home do so for religious purposes (Roach 1988). Divoky reported that "...a majority of home schoolers are religious fundamentalists, unhappy with the failure of the public schools to teach religious and spiritual tenets... "(1983, 396)

In a study of Iowa home schooling, Dahm stated, "The stereotype is that most families home school for religious reasons. Religion, however, is only one of many reasons..." $(1996,68)$. Other reasons for home instruction include student safety, societal influences such as drugs, increased individualization of instruction and philosophical differences over how children should be educated (Roach 1988). Additional reasons noted included negative peer pressure and rivalry and competition experienced in public schools (Maness, 1988).

By interviewing home school parents Gray concluded in 1992 that there were nine overall reasons for beginning to home school. These ranged from (1) values conflict between home and school, (2) wanting to increase family unity, and (3) to the child not succeeding academically in school. The final decision was usually based on a combination of aforementioned factors. "Over $80 \%$ of the families reported being 
influenced by peers, home school organizations, or their churches to begin home schooling" (Breshears 1996).

Van Galen (1986) explained after observing 16 families in North Carolina, that home schoolers generally divided into two groups, "Ideologues" and "Pedagogues." The Ideologues home school because they believe that public schools teach values that are anti-family and anti-Christian and the Pedagogues home school primarily because they believe their children learn best in the informal environment of home. More specific reasons which were common to both groups were also cited. The parents believed that it will strengthen their families, because they fear that their children will be damaged by the teachings of public schools, because they believe that their children learn in unique ways, and because acceptable schools were not available.

"In spite of the diverse reasons that draw parents to home schooling, they share a profound belief that the public schools are not providing a healthy environment for their children" (Divoky 1983, 397). Home school parents tend to see the role of the family as supreme, with the activity of home schooling contributing to the goal of keeping the family unified (Fash 1994).

\section{$\underline{\text { Overview of Curriculum and Materials }}$}

Examining the curriculum used in home schools provides another perspective on the world of home schooling (Lines 1987). Although research is limited, Breshears found in a 1996 study of Idaho home schoolers that the curricular materials were described as being selected to enforce the values of the families. 
Children are formally "schooled" three to four hours per day, and often spend extra time in individual learning endeavor (Ray 1988). Former home-school proponent, the late John Holt, recommended three to five hours of formal instruction a week was sufficient (1983). "There are likely to be a million different ways these students are taught depending on the reasons their parents decided to home school (Rasmussen 1999, 1).

Interviews with home school families indicated that parents think through their methods carefully to meet the individual needs of their children and make efforts to discover an appropriate pedagogical approach for their children. Some families use very traditional approaches, including schedules and lesson plans that tend to look exactly like many of those used in classrooms. Others believe in allowing the children to set the pace and direction of home schooling (Lines 1987). Holt recommended this free-flow of curriculum for home school children and believed that the interests and inclinations of the children should determine what happened (1983).

In a 1995 study, Prince determined that most home schoolers introduce a formal curriculum at the conventional school age and phonics is overwhelmingly the instructional method of choice. "Some home school leaders believe that parents should start helping their children to read or have formal learning sessions as soon as their children are ready, whether it be at 3 years or 10 years of age" (Ray 1988, 18). Others say that children are not ready for "formal learning until sometime between the ages of 8 and 12 (Ray 1988).

Fifty to seventy-five percent of all parents engaged in home schooling design their own curricula rather than use the services or materials from institutions (Lines 1987). 
However, even families who do not home school for religious reasons use Christian religious publishing sources for their curriculum (Prince 1995).

The pre-packaged curriculum from institutions follow no standard pattern, but are usually highly structured. The Calvert School, oldest of the organizations enrolling home-schooled children, began in 1908. Many of the packages are affiliated with religious organizations, such as, A Beka Publications affiliated with Pensacola Christian College, Bob Jones University Press, and Rod and Staff Publications affiliated with a Mennonite group. The Accelerated Christian Education (ACE) materials guide children through a sequential home-study curriculum that relies heavily on Biblical passages and moral homilies. The material shows traditional families and sex roles and take a strong authoritarian approach (Lines, 1987).

In the aforementioned Van Galen study, the identified Ideologues home schoolers often embraced conventional school techniques and materials in their homes while trying to avoid public school values. Pedagogues sought new ways to teach and rejected the formal practices of conventional schools (Ray 1988).

No single characterization suffices in describing all home school curriculum. "They range from the highly structured to the unstructured, and from the home school that follows homemade materials and plans to the one that consumes hundreds of dollars worth of commercial materials every year" (Ray 1988, 17).

\section{Interactions of Home School Families and Public Schools}

Many school districts and home schooling families do not have cooperative relationships and in numerous cases no relationship at all, Holt noted in 1983, "This pattern of cooperation between schools and what we have come to call home 
schoolers exists in a small but increasing number of school districts in different parts of the U. S." (391). "Much can be gained by building cooperative relationships between public school officials and home schoolers" (Lines 1987, 516).

Home schooling is now legal in every state in the Union. Nevertheless, some public educators feel that only public schools can achieve the public's goals for education. "A few state and local educators vigorously oppose home schooling because they believe it is unsound educationally; they dismiss evidence of aboveaverage academic achievement as incomplete" (Line 1987, 516). "Public school advocates sometimes see home schoolers as radicals bent on defying the system..." (Natale 1992, 280). Pennsylvania superintendents who completed a two-round Delphi questionnaire along with selected school principals, state legislators, juvenile court justices, and university professors of education expressed opposition to home schooling (Pitman 1987).

On the other hand, home schooling families sometimes see public educators as crass opportunists, interested in their children only for the federal and state dollars that they afford schools. "Or worse, they see public educators as depraved characters seeking to mold other people's children in all the wrong ways" (Lines 1987, 516). "Many home schoolers say they are reluctant to work with local schools because they fear control will be taken from them" (Rasmussen 1999, 5).

There have been some attempts to keep home schoolers linked with the public schools. In Cupertino Union School District, California, home schooled children are allowed to "enroll" in--without being required to attend--one of the district's alternative schools. The district does receive some state aid and the students also 
receive $\$ 1,000.00$ toward cost, plus optional testing for the child, access to a teacher for concerns, and the chance to participate in any staff-training programs for district teachers (Natale 1992).

Another example of cooperation between home schoolers and public education is in the state of Washington. Home schooled students are eligible to receive part-time instruction in the public schools. "Entry into a part-time arrangement is relatively simple: the state merely reimburses the school district for providing part-time services" (Roach 1988, 13-14).

The Des Moines Public School System was one of the first to offer cooperative home-school experiences for parents who choose to teach their children at home. In that school district eight full-time teachers and one full-time coordinator is assigned to the Home Instruction Program. Each teacher works with a maximum of 20 families or 40 students offering support, counseling, and suggestions to parents and students (Dahm 1996).

Many of those Iowa students take music or band lessons at their neighborhood school. Some attend classes in their favorite subject for one or two hours a day, and they may also participate in extracurricular activities, such as sports teams. Dahm asserted that the pioneering home schooling assistance program gives parents an extra measure of reassurance in their solo approach to education (1996).

Holtrop, educator, researcher, and home schooling parent, noted, "I look forward to a time when superintendents and state education officials will work with home schoolers to offer classes or materials on an as-needed basis" (1996, 74). Many state education agencies do have a home schooling liaison, who at a minimum will assist 
families in understanding state requirements (Lines 1996). Lines observed, "Given the more favorable legal climate for home schooling, families are now freer to concentrate on access to public resources and scholastic and athletic competitions" $(1996,66)$.

Idaho is considered one of the United States' forerunners in home schooling and has active home schooling advocacy organizations. Idaho legislation passed in July 1995 gives home schooled and private school students access to the academic, elective, and extracurricular programs of public schools (Person 1996).

The Edmonds School District in Washington, opened a CyberSchool in 1996 as an alternative school setting just for home schooled students. It began with 35 students enrolled and in 1999 the resource center offers classes to 470 students in grades kindergarten through twelfth grade. "To enter CyberSchool, parents must meet state home schooling requirements and document that they have home schooled for at least ninety days" (Rasmussen 1999, 5). Originally conceived as a distance learning program, the CyberSchool is housed in a former elementary school and students can take part in workshops or work in computer labs. The parents are viewed as the teacher; however, the public school system is there to support and assist in student learning.

West Virginia Code 18-8-1 B(b) states the following regarding the use of resources and class attendance:

The superintendent or a designee shall offer such assistance, including textbooks, other teaching materials and available resources, as may assist the person or persons providing home 
instruction subject to their availability. Any child receiving home instruction may, upon approval of the county board of education, exercise the option to attend any class offered by the county board of education as the person or persons providing home instruction may deem appropriate subject to normal registration and attendance requirements (148).

Many of the home schoolers will eventually enter public schools. The majority of home school families teach their children at home in elementary grades and place their children in public schools for the secondary grades. School districts must be prepared to absorb this population (Roach 1988). Because it is public school's obligation and legal responsibility to ensure that all children within the state are being educated, school officials need to know the values, beliefs, and practices of home schooling families. By knowing more about home schooling families, the opportunities to build a mutual respect, trust and cooperation will increase.

The average home schooling experience lasts only two years (Lines 1996); therefore, public schools need to be aware of this population and their needs. Home school advocate, Bunday, asserted:

"...home schoolers reentering the government-operated school system is one of growing importance for policy makers, who must decide grade placement for home schoolers entering age-graded schools, allocate "credits" toward graduation, or otherwise apply the bureaucratic regulations of the classroom school system to children who formerly learned outside it" $(1988,20)$. 


\section{$\underline{\text { Summary of the Literature }}$}

The trend to home school children has steadily increased throughout the last three decades. Parents are choosing to exercise their right to teach their children at home and home schooled students are estimated to represent one to two percent of the school age population.

Studies of the characteristics of home schoolers describe a diverse population, although the mother is most often the primary teacher. Research also determined the facts that home schooled students score well on standardized tests and seem to be as socially adept as public school children.

The reasons parents choose to home school are varied; however most studies have found that the primary reason was for religious purposes. Other issues that influenced parents to opt to home school include student safety, negative societal influences and philosophical differences between parents and schools.

Home school parents often select curricular materials to reinforce family values and lessons are many times tailored to meet the needs of the individual student. Some home schooling parents believe that the interests of the student should indicate the curriculum.

The number of hours home school students spend in formal instructional time varies greatly. For some it is only a few hours a week, while others spend as much time in formal instruction as the traditional public classroom student. The range in materials and curriculum is from the highly structured to the unstructured.

In the past, many school districts and home school families have had little interaction; nevertheless this trend seems to be changing. More and more home 
school students are seeking out limited curricular and co-curricular classes and activities to supplement their home school education. Because the majority of home school students enter or reenter public schools, it seems apparent that a relationship between public schools and home schoolers needs to be established.

Throughout this literature review, no research was found targeting the transition that children and their families make when they enter or re-enter public schools. Therefore, the point of the study is to discover what are the critical issues embedded in the experience that the home schooled child who enters or re-enters public school, the guardians/parents and educators experience. Furthermore, what do schools do or what could do assist in the transition according to parents or guardians, students and teachers? This will be the first such study in the state of West Virginia. 


\section{Chapter III}

Method of Research

\section{$\underline{\text { Subjects }}$}

The participants in this study were home schooling guardians/parents who have chosen to enter or reenter their child(ren) in public school system in West Virginia and who were willing to be interviewed. The children of those parents were also participants in the interview process. Likewise, public school teachers were also participants. The teachers were identified as those who had the participating student assigned to their classroom for the initial entering or reentering school year and whom were willing to be interviewed.

All home schooling parents, current and those who entered or reentered their children during the school year, were asked to respond to a survey that mainly targeted demographics and the reasons why they choose to home school and the reasons why they selected to return to public schools.

Originally, the primary subjects were to be a four parents/guardians who had selected to enter or reenter their child(ren) in public school, the child(ren) and the primary teachers of the child(ren). However, only three families were ultimately identified to participate in the study. In August of the 1999-2000 school year, all the home schooling families in the school district who had home schooled their child(ren) the previous year and had not filed a letter of intent for the coming school year were identified. Twelve families were identified for potential participation in the study. Of those twelve families five had moved from the area, three had enrolled their 
child(ren) in a Christian school, one had a child who was of age that no longer required them to attend school and three families agreed to be part of the study.

\section{$\underline{\text { Instruments }}$}

Seven instruments were used in the study. A survey and two interview guides for each participant, i.e., students, teachers and parents, were developed and used to guide the research.

All participants, current home schooling families and families who had entered or reentered their children during the school year, were asked to complete and return a demographic survey questionnaire which is found in the appendix, which had multiple choice answers and short written answers. The two page survey asked basic demographic information and covered the following topics: (1) number, sex, and grade level of children home schooled; (2) number of years the child(ren) have been home schooled; (3) the highest level of education the parent/guardian has completed in school; (4) if the parent/guardian or other family member was home schooled; (5) occupations of the parent/guardian; (5) use of technology for instruction; (6) reasons that the parent/guardian chose to home school their child(ren); (7) if the parent/guardian will enter or reenter their child(ren) in public school; and (8) if the parent/guardian has chosen to return or plans to return their child(ren) to public school, the reasons for that decision.

Initially, the survey instrument was reviewed by a home schooling parent who was not a participant in the study. This person reviewed the instrument using a checklist for validation. The checklist validated the following areas: (1) clear and concise 
questions; (2) clarity of interpretation; (3) understanding of terms; and (4)

recommendations for improvement.

The survey was developed using as a guide pervious home schooling surveys developed by doctoral students; the Charleston Southern University, Center of Home Schooling, "Home Schooling Parent Survey" and the aforementioned research questions.

A cover letter was developed to introduce the interviewer and explain the survey. The cover letter also assured the participants that completing the survey was voluntary and that all responses would remain confidential, respecting their anonymity.

The interviews were conducted using guides and were tape recorded. Some field notes were taken and the completed recordings of the interviews were transcribed for analysis. The first interview guide employed was developed from the research questions and the information gathered from the returned surveys. These interview questions were general and open ended in nature. The second set of interview questions were developed after review of the results of the first round of interviews. Some of the questions in the second interview guide were specific to the participant, due to an issue that was initiated by that person. For example, $\underline{\text { Design }}$

Survey questionnaires were sent and a follow-up reminder and survey to all the current home schooling families and those families were identified as having children who had entered or returned to public school. Two rounds of interviews were conducted with three identified home schooling families who had selected to enter or 
reenter their child(ren) in public school, students and public educators. While the information obtained may not be generalized to other settings, this design resulted in findings of more depth and detail than could be obtained by other methods.

Although a survey was employed, the overriding process was dependent upon long, in-depth interviews. Therefore, the main body of the study was qualitative in nature.

According to McCracken (1988):

The long interview is one of the most powerful methods in the qualitative armory. For certain descriptive and analytic purposes, no instrument of inquiry is more revealing. The method can take us into the mental world of the individual, to glimpse at the categories and logic by which he or she sees the world. It can also take us into the life world of the individual, to see the content and pattern of daily experience. The long interview gives us the opportunity to step into the mind of another person, to see and experience the world as they do themselves (9).

While studying the experience of home schooled students' transition into public schools, the perceptions of those involved are the key factors that this interactive design was targeting. Wiersma explained, while discussing research design in qualitative research, "It is the perceptions of those being studied that are important, and to the extent possible these perceptions are to be captured in order to obtain an accurate 'measure' of reality" $(1995,212)$. 
Although many researchers debate the best way to conduct studies, the qualitative method of the long interview lends itself to the embedded details in the relationship between public schools and home schoolers. When addressing qualitative research, Lofland and Lofland, concluded:

The particulars of the source materials may differ...but the essential process is identical to other kinds of intellectual endeavor. The elements of this essential similarity include tenacity, commitment, thought, reflection, critical scrutiny, methodological caution, organization, and flexibility (1995, 229).

\section{Procedure}

Surveys were sent to all of the fifty-nine home schooling families, whom collectively home schooled ninety-seven children, in the school district. The first round of surveys were mailed May 25, 1999 and included a self addressed stamped envelop for the survey's return. Fourteen responses were received. A second round of the same surveys were mailed out seventeen days later, on June 11, 1999. Three additional responses were received.

In total, seventeen responses or completed surveys were returned, for a $28.81 \%$ response rate. Nine of the surveys were return with a message from the post office that the addressee had moved and no forwarding address was available.

The information collected from the survey was then included in the formation of the interview guides for the in depth qualitative study.

Beginning in August 1999, three home schooling families who had chosen to enter or reenter their child(ren) in public schools were contacted by phone to explain the 
nature of the study and to set-up their first interview time. At this time, their willingness to be interviewed as well as the assurance of confidentiality were discussed.

When each family was contacted, they were told that if they participated in the interviews, each of the children in the family would receive a one hundred dollar United States Savings Bond. All of the families who were contacted agreed to be part of the study.

Interview guides were developed from the research questions and the information gathered from the returned surveys. The interviews were to take place during the transition; that is, throughout the student's first school year after entering public education system. In addition to the interviews with the families and students, the student's teachers were also interviewed.

The primary focus of the interview questions was to determine the experience of the transition of the student into public school and the ways in which the family viewed the school's role in making that transition a positive one. Interviews were also conducted during this same period of time with the teachers of the students and the students themselves. The interview questions also dealt with the transition and the adaptation of the student to the format of public schools, both academically and socially. Conversations were tape recorded and then transcribed by me.

Second semester of the school term, one additional round of interviews were scheduled to clarify and delve into answers given in the first interview.

A mutually convenient time and place for the respondent and myself was identified for the interview. The initial interview was always conducted with the 
parent first. At the beginning of that interview the nature of the study was explained and consent forms were read and signed. The parent signed their own consent form and also signed one for each of their children. Additionally, participating teachers read and signed consent forms for themselves.

All of the participants, teachers, parents and students, were told at the beginning of each interview the following (Appendix M):

I want to thank you for allowing me to visit with you here today. I am interested in finding out ways that home schooling parents who choose to enter their children in public school, believe that public schools can interface and assist families in making the transition from home to public school. I would like to tape record this interview so that I may have an accurate record of your responses when I begin the analysis of this data collected. In no case will your name be identified nor will your comments be identified as yours. I would like for you to respond as fully as you can, although, if there are questions that you are not comfortable in answering, then please let me know and you do not have to answer those. If you need clarification of any question, please ask me for further explanation.

Two interviews were conducted with each of parents, students and teachers for a total of 46 interviews. Four of the interviews were conducted at public libraries, four at a private residence and the remainder in public schools. The average length of the 
interviews was forty-five minutes. The interviews were conducted from October 1999 through May 2000.

It should be noted that although both parents were asked to take part in the interviews, in all cases the only participating parent was the mother. There were fathers present in each of the families who participated in the study, and often times the mother referred to her husband and at times related their feelings on topics.

\section{$\underline{\text { Personal Lens }}$}

As in all research, the person conducting the study brings to the study their own insight and background. Wiersma asserted, "Qualitative research uses inductive inquiry, which for data collection means that it commences without any preconceived theories or hypotheses. However, all researchers are influenced by their own backgrounds, and some information is likely to be available about the research problems" $(1995,214)$.

In 1993, I was assigned the task of overseeing the program of instruction in the home, also known as home schooling, as part of my duties as a central office supervisor. At that time, I knew little to nothing about the home schooling laws, numbers of families participating, county obligation or the reasons parents opted for this alternative for their children.

Of course, I knew that home schooling did exist, primarily from infrequent news articles or human interest television stories touting families who lived off the land and taught their children. I recall a news story spotlighting a home schooling family in which three of the children went to Ivy League schools on scholarship. Although this seemed impressive, being a professional educator I wanted to believe that the school 
system could educate better and offer more to students than the home school environment.

After taking over the duty and becoming very familiar with the state code concerning home schooling, I learned very quickly that the relationship between the board of education and home schooling families, in general, was not one of cooperation. Many times the parent was "pulling their child out of school" because they were dissatisfied and/or felt that the school system was not meeting the needs of the child. Even home schooling families that had never had their child in the school system seemed to connote the feeling that it was an "us against them" situation.

Likewise, the county schools system regarded home schooling families with wariness. There is a sincere concern for the child's education and growth to become a contributing citizen. However, additionally there is the fact that school districts are not funded in any way for the home schooled child. Enrollment is affected and the number of teachers that the system is able to employee decreases.

Another phenomena I observed, was that children who had never been to public schools were entering our system. Perhaps more common is the scenario of a child beginning public school, then being home schooled, and then returning to the public school system.

This particular occurrence, that of many home schooling children returning to the public school system, made me wonder about the transition of home to school for all those involved. How did the children cope, what were the parents' experiences and what was happening in the schools throughout the transition? 
Thus, I begin to research the subject and found very little information on the topic. Although there were some studies on the reasons why parents choose to home school, there were virtually no studies on the reasons they return to school and what happens then. Therefore, I designed my research to address this timely issue.

\section{$\underline{\text { Data Analysis }}$}

The information gathered was analyzed and a descriptive narrative summary, conclusions and implications presented. The survey information was summarized in narrative format, averages given whenever possible, and presented in graph or charts for ease of review.

The interviews were audio taped and transcribed. After review of the transcripts, the documents were color coded to signify emergent issues. The emergent issues were then combined when possible and applicable. Finally, seven emergent themes were identified through the interviews. Those issues were: the importance of conferences among parents, students and educators before the student returns to public school; the viewing of "parents as teachers" and the attitude of public teachers toward home schooling; the importance of the home schooled student entering public school to establish social relationships with peers and adults; support that is needed from the public school teachers; academic experiences in the transition; the advantages of attending public school on a part time basis for a limited transition time or as an unlimited educational choice and open communications between families and public schools throughout the home schooling experience.

The original research questions were reviewed and the emergent issues classified and organized to correspond with the appropriate research question. One emergent 
issue did not fall into any of the original research questions; therefore, it was addressed as a separate issue. The issue that stood alone was the advantages of attending public school on a part time basis for a limited transition time or as an unlimited educational choice.

It should be noted that to protect the privacy of the participants, all the names of the families used in this document are pseudonyms.

$\underline{\text { Time Schedule }}$

Event

Contact Superintendent

Surveys sent to all home schooling parents, current or ones which have (re)entered their child(ren)

Second round of surveys sent Introduction to contacts via phone

First round of Interviews

Second round of Interviews

Data Analysis

Report Writing

Study given to Committee
Beginning and Ending Date $5 / 99$ $5 / 99$

$6 / 99$ $8 / 99$ to $10 / 99$

$10 / 99$ to $12 / 99$

$1 / 00$ to $5 / 00$

On-going to $7 / 00$

$7 / 00$ to $12 / 00$

$12 / 00$ 


\section{Chapter IV}

\section{Research Findings}

Chapter IV conveys information resulting from the surveys and the in-depth interviews. As a consequence of the information gathered, seven emergent issues were identified. Those emergent issues will also be presented in this chapter.

The limited studies which have addressed the concept of home schooling have focused mainly upon its demographics as well as the reasons that lead to making the decision to home school. Most home schooled children will enter public school at some point in their educational careers. Studies addressing the issues related to the home schooling students' transition into public schools have been very limited.

This study addressed the issues embedded in the transition of home schooled students entering or reentering public schools. Although the main form of research employed was qualitative, an initial survey was also used to identify some demographics and introduce myself to the home school families. The information gathered in the survey also assisted in the formulation of the interview questions.

The results of the study are reported in this chapter. The primary purpose of this study was to provide answers to the research questions presented earlier in Chapter I:

1) What are the factors that influence the home schooling family's (parents'/guardians') decision to enroll or re-enroll their child(ren) in public schools?

2) What do home schooling guardians or families, who choose to enter or re-enter their children in public schools, believe public schools currently do and/or should do to support their children in their transition from home to school? 
3) What is the experience that home schooling students have upon entering or reentering public schools and what could the public schools do to participate in that experience? What is the role of the public school in that experience?

4) What are the critical issues embedded in the transition from home schooling to public schools for guardians/parent, children and educators?

The results of the information gathered from the survey and the parent, student and teacher interviews employed in this study are presented in this chapter.

Although the response rate $(28.81 \%)$ was disappointing, the survey was not the basis nor the crux of the qualitative study. The survey was conducted to glean some background demographic information; insight into why families home school and why families chose to return to public education.

Valuable information was gathered in the two questions that required a narrative response on the survey. In most cases families were willing to answer these questions in detail and a substantial amount of information was colleted from the responses.

Of the seventeen families who responded to the survey, the number of children involved in home schooling was double that amount. The families were currently home schooling 35 children in grades kindergarten through eleventh grade.

\section{The Survey}

The home schooling parent survey in its entirety may be viewed in Appendix B. Questions one through nine were developed to get a glimpse of the home school family and establish some background demographics. Questions ten through 13 were designed to find out why parents began to home school their children; if the parents 
were planning to enroll their children in public school in the future and, if so, why they planned to enter their child in public school.

All of the seventeen of the families responding to in the survey were home schooling their children at the time. The total number of children in the families was thirty five.

The families had home schooled their children for a total of 139 years and the average number of years students were home schooled was 3.97. Eighteen of the students had been in public school at one time before being home schooled, while 17 had been home schooled for their entire educations.

The average age of the student being home schooled was 11.19 years. The average grade level in which the students were being taught was 5.42, with a range of kindergarten through eleventh grade. One family selected not to respond to the question regarding the age of their children. Eighteen of the students being home schooled were female, 12 of the students were male, however, the sex was not given for five of the students.

The parents had a very diverse range of level of education. The mothers' level of education varied from a high school degree or GED to a Master's Degree. The average level of education for the mother was two years of some sort of higher education. The fathers' education level was even more extreme in range-from less than twelve years to a Doctoral Degree. Although, again, the average level of education for the father was approximately two years of higher education. A chart in Appendix D indicates the education level of each parents. 
While fifteen of the parents indicated that they had not been home schooled, one parent had been home schooled and attended public school during her educational career. Twelve of the families indicated that no one else in their families had been home schooled, whereas, four responded that someone in their extended family had had a home schooling experience.

The occupations of the parents differed vastly. A chart in Appendix E displays the occupation for each of the responding parents. The most common occupation was housewife or homemaker, with eight parents indicating this area. Three of the parents shared the occupation of nursing. Additionally, three other parents were employed in the medical field, one as a pharmacist, one as a doctor and one was not specific, indicating only "professional medical field." Occupations that were common to two parents were teacher and minister. Additionally, two of the parents were disabled.

Fifteen of the families indicated that there was a computer in the home, while only one did not have a computer. Thirteen of the families used the computer to deliver instruction for the student, while only one family reported that they did not use it for instruction.

Twelve of the families belonged to a home school association. (This information indicated that the chances that I would interview a family that participated in a home school association were great. However, none of the families interviewed were associated with an organized group for home schooling.)

The reasons given as to why families first choose to home school their child(ren) varied substantially. Full responses to this question are given in Appendix G and a summary chart of those responses are in Appendix H. The most frequent reason given 
had to do with religious issues. Seven families cited religious issues as one reason or the only reason that they home schooled. Of the seven families citing religious issues, three of them had always home schooled their children, while four families had children that had been enrolled in public education before they decided to home school.

The next two most frequently given reasons were safety of child(ren) and the belief that a better education could be provided at home. Five families cited safety issues and six families believed that they could provide a better education at home as the reason that they began to home school their child(ren).

Other reasons that two families indicated were 1) control of behavior/control of discipline, 2) socialization, 3) bullying in school, 4) individual attention and 5) treatment by teacher/uncaring school system.

All of the other reasons given as to why the families began to home school were only mentioned by one of the families. However, there are several reasons given that could be combined, i.e., socialization, bullying in school and student unable to cope. Although it is difficult to know decisively if the responders would agree that these categories were common ones, if combined the responses would total five.

It should be noted that the question which targeted the "reasons parents select to home school their children" ask for a narrative answer; therefore, multiple reasons could be given. As the research indicated, the reasons that motivate families to home school their children were widespread. Nevertheless, religious reasons was the most common answer, again just as research noted. 
Three of the families had preschoolers in their homes and two of the families planned to home school those children, also. Three of the families planned to enter or reenter their children in public school in the future, one family planned to enter their child in a Christian school and two of the families were undecided. Of the three families who planned to enroll their children in public school, two of the families indicated that they would do so in the ninth grade and one in the fourth grade.

Seven families responded to the question, "If you have chosen to return or plan to return your child(ren) to public school, describe the reason(s) for that decision." Again, a narrative response was required, so more than one reason could be given per family. The full response of each family may be found in Appendix $\mathrm{H}$ and a summary chart in Appendix I.

The only response that the families had in common was to provide socialization and interaction with peers, with two of the families indicating this reason. The other reasons given were: 1) would return if Bible were taught in public school, 2) burnout of the parents as the teacher of the child(ren), 3) exposure to other ideas, 4) to enroll in a specific classroom to be taught by a specific teacher, 5) attain a high school diploma and 6) the parent did not meet the minimum state requirements to teach the student at home.

The survey served to give a "flavor" for the diversity of the home schooling families. Because of the low return rate it is difficult to determine if this is representative of the majority of the home schooling families in the district; however, the data collected did support and confirm that of previous studies in this area. 


\section{The Interviews}

All the interviews were audio taped and transcribed. After all of the interviews were completed and the transcripts reviewed, there were a number of issues that emerged as key components in addressing the aforementioned research questions.

The following seven issues regarding the transition were common among all those that were interviewed:

- the importance of conferences among parents, students and educators before the student returns to public school;

- the viewing of "parents as teachers" and the attitude of public teachers toward home schooling;

- the importance of the home schooled student entering public school to establish social relationships with peers and adults;

- $\quad$ support that is needed from the public school teachers;

- academic experiences in the transition;

- the advantages of attending public school on a part time basis for a limited transition time or as an unlimited educational choice and

- open communications between families and public schools throughout the home schooling experience.

Each of the issues that emerged will be explained further and, in Chapter VI, conclusions will be drawn to address the original research questions.

The interviews were conducted throughout the school year, from October 1999 to May 2000. All of the interviews were conducted in a face to face situation in homes, public libraries or public schools. 
To establish a framework for the reader, a description of each of the three participating families is provided. This description includes a brief history, the reasons why the families began to home school and the reasons why the families returned their child(ren) to public schools.

This type of description is not provided for the teachers who participate. Although many insights were gleaned throughout the interviews, the personal backgrounds of the educators were not targeted in the study.

Introducing the Participants

\section{The Adams Family}

The Adams family had two children that had been home schooled for one semester the previous school year and had returned the children to public school. After contacting Mrs. Adams by phone and briefly explaining the study, she agreed to meet at a public library to talk further.

Mrs. Adams was originally from Ohio and attended public school there. Mrs. Adams appeared to be in her forties, had brown, shoulder length hair and was dressed casually in blue jeans and a t-shirt. Mrs. Adams finished high school, but did not pursue any higher education. She had home schooled two of her children the previous school year, Megan, presently a fourth grader, and Evan, a sixth grader. Mrs. Adams also has two other male children, one in twelfth grade and a freshman in college.

When asked if anyone in her family had ever been home schooled before, she said that both her older boys had been and Evan for his kindergarten year. She explained that her oldest son had entered kindergarten in public school in Virginia. He was held 
back in kindergarten for a second year and then after his first grade year the school system wanted him to repeat that year, also. It was at this point that he was tested and identified as having Attention Deficit Disorder (ADD). Mrs. Adams stated, They [the public schools] weren't equipped to handle the kids there in that school for ADD because they would have to be sometimes put off in a room by themselves under observation by people. They can't learn by themselves. That was his problem and when he got in the classroom he was totally disrupted by what everybody else was doing. He had to have individual instruction.

Mrs. Adams then removed both her older sons from public school and enrolled them in a Christian school. After one year in Christian school, Mrs. Adams became pregnant with Megan and experienced difficulties and had to become mostly bedfast. At this point, she decided to home school her oldest two boys. After one year, the family moved back to Ohio, where the boys were enrolled in public schools. Her oldest son soon began to experience problems in the public schools. Mrs. Adams explained,

They had a lot of problems with him in public schools because they still didn't know what to do with him. I told them to be as strict as possible. Make him do his work, don't give him a choice because he was so use to me being real firm. He ended up getting detention all the time. When he started junior high up there, that was just as bad. There was [sic] a lot of young teachers. They met with me every week trying to figure out what to do. So, I just took him 
out and home schooled him.

Mrs. Adams also took her second son out of public school and when Evan was old enough to begin kindergarten she also home schooled him. Mrs. Adams home schooled for two years, until the Adams moved to West Virginia and they decided to “...give it another chance." The two oldest Adams children entered junior high school and Evan was enrolled in first grade. The two older boys continued to experience some problems with academics and "getting detention" until they became high school students and then Mrs. Adams felt that they “...ended up doing so well there.”

By this time Evan was in fifth grade and Megan in third grade. During this time Mrs. Adams was involved in volunteering at the elementary school and became PTO president for the 1997-98 school year. When Megan entered the third grade she began experiencing problems in school. Mrs. Adams observed, "I am so use to being involved in my kids' life, I just don't like just sending them off to school and letting the teachers take care of it. I just can't stand that because it's their responsibility to teach not to train them. So Megan got a new teacher and we kind of butted heads real bad.” Mrs. Adams further explained, “The first three months of school Megan was failing bad and in third grade, there is no reason why a third grader should be failing like that."

When talking about Megan's third grade problems, Mrs. Adams stated, "My kids are important. You know, I've got to do something. I've got to figure out why and how to help them." Mrs. Adams contributed this strong feeling to her past and explained, “My parents didn't really care. They just demanded that I make straight As 
or whatever and I never could and they didn't bother. They would always put me down for this and that. I just wanted out of school and I didn't care how I did it."

The school system wanted to test Megan for a learning disorder and Mrs. Adams did not believe that it was necessary. Mrs. Adams felt that Megan “...had a little comprehension thing, but it's not real bad" and did not do well when there were time constraints. When the teacher and Mrs. Adams continued to have conflicts over the correct way to teach Megan, Mrs. Adams removed both Evan and Megan in the middle of the school year.

Mrs. Adams planned to continue to home school the children, but a few weeks before 1999-2000 school was set to start, Mr. Adams decided that Megan and Evan should return to public school. Mr. Adams wanted Megan to have a certain teacher in the fourth grade, who the Adams respected. Mrs. Adams said that both of the children wanted to continue to be home schooled. She stated,

Evan loves to be home schooled. He said, 'Mom, I remember when you did me in kindergarten.' He liked it but I am harder on them at home. I give them more work. They don't get up until they get finished because I have that opportunity. Megan didn't want to go back to public school because she was afraid she would get the same treatment. She was afraid that she would disappoint the teacher or not be good enough in her math and comprehension. This year she said, 'Mom, I'm scared I'm not good enough' and that gave her a really big complex. 
When asked if Mrs. Adams and her husband discussed returning the children to school, Mrs. Adams said, "No, he just said, 'No-they are going back this year.' I knew I had to think about it and make sure that's what God wanted me to do, but then I said, 'Let's give it a chance.'”

During the second interview, Mrs. Adams explained further why her husband wanted the children to return to public school,

He thinks it's just too much pressure on me because he knows what I go through with them to make them do it and finish it. I push them.

I guess I probably push a little too much. He knows I do that trying to shove it in there because I guess I'm worried about them not knowing enough or something like that or I'm going to get into trouble if I don't teach them this, this and this or something like that.

Evan Adams entered sixth grade, in a school that houses kindergarten through eighth grade, in August of 1999. He has a homeroom and five different teachers who operate with a middle school philosophy. Megan Adams was enrolled in the same school in the fourth grade.

\section{The Bailey Family}

The study was explained to Mrs. Bailey in a phone conversation and she said that she would have to talk with her daughter, Rebecca, before obligating them to be part of the study. In a few days, Mrs. Bailey called to say that they would participate and arrangements were made to meet at a public library.

Mrs. Bailey grew up in a neighboring county, where she attended public school and then attended four years at the state's university. She explained that after her 
previous marriage "broke up" that she returned to her present location and received an Associate Degree in nursing from a local college. She married and had one daughter, Rebecca, and a step-daughter from her husband's previous marriage, whom they did not raise. Although Mrs. Bailey has worked outside of the home in the past, she is not presently employed. Mrs. Bailey, a petite, white woman, is in her forties.

No one in Mrs. Bailey's family had ever been home schooled before. Rebecca had attended a small elementary school that serves mostly a high socio-economic group of students. When Rebecca graduated from the elementary school and began attending middle school with students from five other feeder schools, she became unhappy with school. Mrs. Bailey explained the “...reason we pulled Rebecca out...was mainly a social thing." Mrs. Bailey stated,

The middle school was a very difficult transition for her. Going in the sixth grade, she was a little kid, she was terrified and a lot of the children, probably who had been held back and were quite a bit older, they were in her class. They cussed her and they sprayed her with pop and food and it was just very, very unpleasant. She cried the whole semester we left her in. It was just misery.

Rebecca was removed from public school after the first semester of sixth grade and home school for the next year and a half. Mrs. Bailey enjoyed her time with Rebecca during home schooling and stated, "It's just the maturity of this kid is just amazing in the last two years." When asked if she thought that home schooling helped that maturity, Mrs. Bailey stated, "I think I helped bolster it somewhat. You know it's hard to tell what did. My guess is that she would have been very, very 
miserable if I had left her in public school that year and it might have damaged her self-esteem even more."

Mrs. Bailey also believed that she and Rebecca were able to cover more curriculum while home schooling. Although Rebecca was a little worried about where she would be academically compared to her peers, Mrs. Bailey believed Rebecca would compare favorably with other students after being home schooled.

Rebecca Bailey initiated her own return to public school. Mrs. Bailey explained, "She came to both of us and said that she was basically lonely and we had severe reservations, we really did, based mostly upon the reason we had removed her from public school..." Although the parents had reservations about Rebecca returning to school, she was persistent. Rebecca stated, "I just kept assuring Mom-I would say, 'I really miss my friends' and I'd drop hints that I wanted to go back. Then I started to ask straight out, 'Can I please go back?' I spent most of the summer begging them."

Rebecca convinced her parents to let her return to public schools and enter the eighth grade in a sixth through eighth grade middle school in August of 1999.

\section{The Carter Family}

Contacting the Carter family was difficult because they did not have a phone. Contact was made with Mrs. Carter's father by phone and the study was explained to him. He then contacted his daughter and who then called to set up an interview date and time. That appointment was broken when the Carter family experienced some housing difficulties and eventually moved across the county. Mr. Carter was out of 
work and they could not afford the housing they were previously living in. Her children were transferred to another school within the district when they moved.

Contact was again made with Mrs. Carter's father and eventually, Mrs. Carter agreed to be interviewed in her home. The home was a single wide trailer located in a very rural area, off a gravel road.

Mrs. Carter, a white woman in her late thirties, grew up in New Orleans. She finished high school education in same district in which she presently lives, attending vocational technical education classes. In the past, she has worked outside the home “...a little bit here and there." No one in her family had ever been home schooled before she began home schooling her children.

Mrs. Carter has three boys, ages thirteen, twelve and nine. The oldest son had never been home schooled and is presently in the seventh grade. Ryan Carter, twelve years old, began his home schooling in the second grade along with his brother David in kindergarten in another school district in the state. Mrs. Carter explained,

The reason we stated home schooling Ryan was because Ryan had a lot of problems in school. He had a lot of problems interacting with other kids and things like that... and they were going to send Ryan to like a special education school. Very reluctantly I agreed to it because I didn't understand things that were going on. I sat home for about two weeks, never heard anything else from the people. He sat home with me not doing anything and not learning anything. I just got fed up...that's when I initiated home schooling. 
Over the next four years the brothers, Ryan and David, were home schooled "off and on" according to Mrs. Carter. Periodically, the boys would be returned to school to "try it again." The boys continued to have "behavioral problems" and "were picked on or made fun of" and were again taken out of school after only a few weeks. Mrs. Carter "thinks" that they tried to put the boys back in school two times over the four years.

Mrs. Carter and her husband decided in the early summer months of 1999 that Ryan and David should return to public school "to be around friends." Mrs. Carter explained, "I think scholastically it's better on them to be home schooled. Academically, it's better for the boys but they also need friends, too." After the decision was made the parents told the boys that they would be going back to school. Mrs. Carter described their reaction, "David immediately wanted to go back because he does real good as far as the public goes. Ryan was a little reluctant but he wanted to go back too because he saw the things his older brother got to do and he wanted to do it. They were okay with going back to school."

In August of 1999 Ryan and David Adams began to attend public school in a kindergarten through eighth grade school, David in the fourth grade and Ryan in the sixth grade. Immediately, David began to experience problems and after two weeks he was removed from public school and his mother began to home school him again. Mrs. Carter explained,

I started David back in public school the beginning of this year, too but to be real honest with you, his teacher was very... kind of like, I felt like she was biased because David had been home schooled. 
She verbally made fun of some of his subjects and his abilities.

I went to the school board. She picked on David every day. She constantly picked on David about something. She would make remarks to him in front of the class that would humiliate him.

So I just said, 'I'm not going to have him go through that.'

David Adams was removed from public school, however, sixth grader, Ryan continued to attend. Ryan was transferred after Christmas 1999 to a school across the county when the family moved to another location within the county. (Teachers from both schools Ryan attended were interviewed, along with David's fourth grade teacher who taught him for several weeks.)

It should be noted that after the completion of the interviews and the study, Mrs. Carter called the board of education to report that she was going to begin home schooling all three of her children. With less than four weeks left of school, she stated that other children were "picking on" her sons and that she was removing them from public school. Mrs. Carter was told that she needed to file a letter of intent, as required by law. No letter of intent was received by the board of education and the boys were not attending public school; therefore, the county attendance director made several home visits, but found no one at home. On the attendance director's third attempt to make a home visit, he found a sign on the front door that read: "I pay my taxes, I pay my rent, I home school my children, leave me alone.” 


\section{Emergent Issues}

There were a number of issues that emerged as key components in addressing the aforementioned research questions upon review of the transcripts of the interviews. The following seven issues regarding the transition were common among all the participants that were interviewed. Each of emergent issues will be examined and in Chapter VI conclusions will be drawn to address the original research questions.

\section{Conferences among parents, students and educators}

All of the families and educators interviewed voiced the opinion that it would be beneficial for a meeting to take place between the parent and the teacher before the home schooled child began attending public school. Both parties felt that an exchange of information, dealing with such items as learning styles of the students, curriculum, and potential problems, would be very valuable. Many of those interviewed also thought that it would be advantageous to include the student in the conferences.

Additionally, teachers thought that the conferences would be beneficial to glean information regarding the student's social adeptness and their academic abilities before the child entered school. Parents voiced a concern about teachers being patient and caring toward the student and felt that this would be an important topic to discuss.

Even though the benefits of the aforementioned conference seem to be a commonly held belief between educators and home schooling families, oddly enough, only one of the parents, Mrs. Adams, met with the teacher before their child began attending class. Although Mrs. Bailey did not schedule a formal conference before Rebecca returned to school, she did speak with most of her daughter's teachers at an open house which took place in the first few weeks of school. 
However, a conference between the home schooling parent and the public school teacher was not the norm. To add to this lack of communication, many of the teachers who were going to have a home schooled child in their classroom were never notified by the parent or the administration of the school that this was to occur. The phenomena made it impossible for the teacher to initiate a conference.

Of the fourteen educators interviewed, five of them were aware that a student would be entering their classroom who had been home schooled in the past. Of those five, only one was made aware of this fact through the school administration, the other four heard by word of mouth or were aware of the situation because they knew the family. Several of the teachers were told after a few weeks when they made inquires regarding the student through the school office.

When the teachers were asked if it would have been helpful to know that a student entering their classroom had been home schooled, one public school teacher commented, "It would help you to understand where that child is coming from... I think you should know because children that have been home schooled, it is a different atmosphere, not that you would want to be prejudiced against the child or anything, but that you need to know what atmosphere the children are coming from." Another teacher stated,

I feel that information would be important to identify that student, to see perhaps what classes he was taught at home compared to what we offer in the public school system and to try to see if there were any similarities or things that have been taught already or what he may be lacking in skills that he may not have had already and this 
kind of thing.

Several of the teachers felt that they could better serve the child if they were made aware of the student's past experiences, not just academically, but socially. Another teacher commented,

It may not be that they would be behind academically but there are other areas like socialization. They may find it difficult getting along with students. They may not have been interacting with extra activities outside school with other students. So, I think it is our responsibility as a teacher to work with these students. So, I definitely think we need to be told.

When parents and teachers were asked what kinds of information could be exchanged in a conference before the child attended public school many issues were cited. A middle school teacher said, "Well, basically I would like to know how well they had done with the curriculum that they were using. I would like to know the particular reason from the parents as to why they may have been removed from the school. If there were health problems..."

Another teacher thought that potential problems could be avoided if some background knowledge of the child were available. The teacher suggested, I feel it would be beneficial to have some background information, especially if they were home schooled for religious reasons and especially where I teach Science. There are a lot of controversial issues and I should be aware of those so I can make the student and the parents feel more comfortable about my approach to those 
evolutionary topics and things like that."

Teachers seemed primarily concerned about knowing what curriculum the students had been exposed to; what level the students had attained and the ability of the student. A math teacher pointed out that the parent could help with specific skills, stating that the parent could inform the teacher that the student is having problems in a certain area and gave this example, "Well, the student is having difficulty with division, but he does well with proportion. They could point out specific strengths and weaknesses that they've noticed." An English teacher suggested, "Samples of his work would have been helpful. What specific areas were covered with him---nouns, pronouns? Had prepositional phrases been covered? I would liked to have seen the materials that were used and to see how they might have followed along with the textbook we were using."

Students also realized the need to share information. Fourth grader, Megan Adams, who did meet with her teacher before returning to public school, was asked to identify some of the items that were discussed in the meeting. She replied, "Well, I told [the teacher] that I didn't hardly understand my comprehension in reading and she said that she'll help me on it and everything." When twelve-year-old home schooled student, Evan Adams, was asked what kinds of things he would have liked to have talked with his teacher about before returning to public school, he replied, “Like maybe stuff I didn’t know about and stuff I already did [know] and stuff I would be doing in sixth grade."

One fifth grade teacher suggested, "I feel like we needed some test scores or something from the year before. When home schooled children start school with you, 
you need to know where they are." A middle school teacher contended, "I think, if the parent and the teacher met, that conference would be key."

While teachers were primarily concerned with curriculum and the types of material which were covered, they also believed that parents could guide teachers regarding the learning style of the student. One educator observed, "[There are] a lot of little keys that I think the parent will probably have better insight into." This thought was supported by other educators, one of which stated, Most parents are going to have decent insights... Having home schooled them, then they also have some experience in schooling and then as an educator they should realize that this is going to be better for my kid because they need this, that and the other. If that parent can tell us ahead of time, 'If you can try to include him with more groups' or 'If you can try to make sure that he's always looking at you, always seat him so he's looking at you because I have noticed that he doesn't pay attention well...'

Several of the parents also felt that they could offer direction in the area of the learning styles of their children. Mrs. Adams suggested, "Like if a kid needs something explained, they can't sit and read the directions, a teacher should definitely know that."

Although both teachers and parents indicated that information regarding learning styles would be beneficial to discuss before the student enters public school, none of the parents were ever asked about the learning style of their child. Mrs. Carter, who returned two children to public school explained, "I don't remember any teacher ever 
asking how [my child] learns, but every child learns differently. Just like if you correct a child, you can't correct every child the same way. You can't teach every child the same way. They're all different."

Another area that emerged when discussing what kinds of information needed to be exchanged in a conference before returning a home schooled child to public school was that of the expectations of the teacher for the student. Mrs. Bailey, the parent of the eighth grader asserted,

I would beg them [teachers] to have a little bit of patience that first month and please, please, please tell me if there is anything I can do to make it easier. You don't get a lot of feedback from school, especially after grade school and you're not sure when you should interfere or not and it looks to me like the teacher would have a little more insight into it. For example, tell the parent when you need to come in and talk.

Teachers also recognized that parents needed to be reassured regarding what was expected. The one teacher that did have a conference with the parent before the child returned to public school observed,

I think that she [the parent] wanted that reassurance about what my expectations for her [the student] would be and that I was going to treat her kindly and caringly and help her feel comfortable about coming back rather than making it an embarrassing kind of situation. So, I think, as much as anything it was more reassuring for her [the student's] mom. 
More than one parent and educator suggested that it should be mandatory that the home schooling parent and the public school teacher meet before the child enters school. However, whether they felt that it should be mandatory or not, all the home schooling parents and public school teachers believed that it would be beneficial for the transition of everyone concerned to have a conference before the home schooled child entered public school. The conference would address such areas as the curriculum utilized in the home schooling situation and in the public school; learning styles of the home school student that had been observed by the parent; socialization skills of the home school student and the academic ability and level of the home school student. Ultimately, the conference would serve to open the lines of communication and reassure the parent and student.

\section{Viewing "parents as teachers" and attitude of public teachers toward home}

\section{schooling}

While discussing the need for a conference between the parent and the teacher before returning a child to public school, an issue emerged regarding the ability of the teacher to consider the parent a teacher. A further outgrowth of this issue, was the teacher's attitude toward home schooling in general.

Socialization was the main area of concern that emerged with teachers. Teachers questioned if the home schooled child received enough socialization with peers and the correct instruction in some subject areas. One teacher explained,

I think that it hurts the home schooled child. He needs the socialization. I question whether parents totally know how to teach all subjects. I know myself, I can't teach math so I would not want to teach my 
child math. I think they're [the student] hurt by it. You'd have to have a parent that's awfully good. If you had a certified teacher that was working with a child, then that might work.

Another educator concurred, "I feel like home schooled students are missing out in regard to their social skills, being involved with activities that are offered them. Socialization skills are very important in growing up and to establish friends and to participate and be involved in school sports and activities." While one of the teachers said that she had no problem with people home schooling their children, she conceded,

I know some teachers' personalities that it would make a difference, and not a positive difference. I think they would treat the children different because there is a resentment when a child has been home schooled, that it's a personal insult to the school system. That they [the parents] are saying you [the school] are not good enough, I'll keep my kid at home.

Several teachers mentioned that they thought that children needed to be exposed to other children in different races, economic backgrounds and religions. A middle school teacher explained,

Socially I think kids need to be around a lot of other kids and then a lot of the hard knocks type learning takes place. You can't really get it if you don't have more of the different parts of society represented like you would in a public school. Instead of everybody being from the same gene pool, you've got different races and 
different economic backgrounds and so many different types of

kids. I think you need to learn about the world that way.

Although a negative general feeling toward home schooling was the prevailing attitude of the teachers interviewed, when questioned about a specific student that had returned to their classroom, in all but two cases, the teachers had not observed any of the things that they had characterized as potential problems. The majority of the teachers stated that the returning home schooled students were well adjusted, had made friends and seemed to be on level or above level academically.

All of the parents interviewed felt like the teachers did not look upon them as qualified teachers and that there was a general lack of understanding of home schooling by the public educator. Mrs. Adams, the parent of two returning home schooled children explained,

Every time I walked in the school, I just felt like the teachers were thinking, 'Well, you weren't qualified to teach because you didn't go to college.' But, I feel like every mother is qualified to a certain level. I'm responsible to teach my kids what they need to know. That was the biggest pressure for me in home schooling that I had, was to make sure that they learn. I was harder on myself than I was the kids.

When the teachers of Mrs. Adams' two children were interviewed, they had a different attitude toward the parent home schooling than the parent had perceived. The teacher of her fourth grader, Megan Adams, stated, "What I would do, is just talk with the person that was in charge of the schooling, the mother or the father, just like 
I would a teacher." Two of Evan Adam's teachers voiced the same approach. One teacher stated, "I think it would be important that the home schooling parent feel like they're qualified to teach at home. I think they should come and speak to the teacher like a teacher so that when they first come in they would give some credence, credibility to the home schooling program." Another of Evan's teachers concluded that when talking with the parent, "It would be like talking to last year's teacher."

Mrs. Bailey, the parent of the eighth grader, said that she did not think that she was looked upon as a teacher by the public school teachers when they talked, when actually the opposite was true. Mrs. Bailey was a registered nurse, but the public school teachers mistakenly thought that she was a certified teacher. One of the Rebecca Bailey's five teachers said,

I think I could have listened to her as a teacher because when she came to Open House we talked and she was concerned and interested about how well Rebecca was doing with her writing skills because she realized how important they were. It didn't take very long to talk with this lady to know that she was on the ball and I think I could have talked with her as well as anyone.

A middle school teacher felt that she could have a "teacher-teacher conference" with the home school parent. The teacher explained, "The parent has been the teacher and I might even take some things that we've been doing and show them and say, 'Now, have you talked about these different things,' so I would know. You have to have a starting point and I think it would benefit the child, and the parent..." 
When interviewing a group of middle school teachers, one teacher admitted that it would be difficult to talk to that parent as a teacher. She stated, "It would be hard. I don't know if we've [teachers] set ourselves on a pedestal or not, but you do sometimes feel you're more qualified than them [home schooling parents]."

All parents in the study felt that the public school teachers would not view them as teachers. However, most of the teachers said that they would be able to talk with a parent, that had home schooled their child, as that child's teacher. Even though there seems to be an agreement on the importance of discussion between a home school parents and the teachers, this is not taking place. There is very little to no discussion regarding learning styles of students, curriculum or ability level before the home schooled child returns to public school.

It appears that teachers do have an overall negative attitude toward home schooling, however, when asked about a specific student, most teachers did not find the problem with socialization of the returning home schooled student that they had generally perceived. One of the parents felt that there needed to be more of an understanding of home schooling by the public school teachers. The parent asserted, You know, just let them [the teachers] know more about home schooling, because a lot of teachers have this cut and dried opinion of it. It shouldn't be that way because a person should be allowed to teach their child if they're able to do that and their child can keep up. With some teachers I feel like it bothers them when a child gets home schooled. I really do. I think the teachers in public school should be made to understand more about home schooling. 
Home schooling parents do not feel that they are thought of as teachers by the public school teachers. In contrast, public school teachers do seem to respect the parent as the home schooled child's teacher and seem willing to accept information from them regarding the child.

\section{Importance of social relationships}

All of the students in the study left public school and ultimately returned to public school, due to social relationships with peers or school personnel. All three of the families involved in the study had enrolled their children in public school and after a period of time decided to home school. The social issues which caused a family to began to home school were either relationships with their peers or a relationship with a teacher.

Two of the families, the Baileys and the Carters, cited relationships with other students as the reason that they began to home school. Mrs. Carter explained, "The reason that we started home schooling was because Ryan had a lot of problems in school. He had a lot of problems interacting with other kids and things like that." In fact, Mrs. Carter had returned the child to public school two times and began home schooling him again because he had difficulty getting along with his peers. Mrs. Carter stated, "He tried to go back to public school and did really well for awhile and then he started having the problems again. So, I started home schooling him again and he's been back in public school since the beginning of this year."

One of the students, Rebecca Bailey, began to have difficulty when she started sixth grade at a middle school. Her mother described the experience,

The middle school was a very difficult transition for her [Rebecca]. 
Going in the sixth grade, she was a little kid, she was terrified and a lot of the children, probably who had been held back, were quite a bit older, they were in her class. They cussed her and they sprayed her with pop and food and it was just very, very unpleasant . She cried the whole semester we left her in. It was just misery.

Another family, the Adams, decided to home school two of their children when Megan began to have academic problems in the third grade and the teacher and the parent "butted heads." Megan Adams also expressed feelings of dislike for her teacher. The Adams had home schooled several of their other children previously and decided to take both their youngest children, Megan and Evan, out of public school at the end of the first semester of school that year.

Ironically, the parents or the students initiated the return to public school because of a social relationships. Of the five home schooled students, one of them, Rebecca Bailey, asked her parents if she could return to public school. The parents of the other four students, approached their children about returning to school to be with friends or a specific teacher.

Middle school student, Rebecca Bailey explained, “I just kept assuring Mom-I would just kept saying I really miss my friends and I'd drop hints that I wanted to go back. Then I started to ask straight out, 'Can I please go back?' I spent most of the summer begging them." The parent, Mrs. Bailey, agreed, "She came to both of us [parents] and said that she was basically lonely and we had severe reservations, we really did, based mostly upon the reasons that we removed her from public school." 
Mrs. Carter stated, “Academically, it's better for the boys [to be home schooled] but they also need friends, too." This mother observed, "I think when they're completely taken out of school, it does hurt them as far as that aspect goes with friends. I think they're lonelier." Further, Mrs. Carter explained, "I wanted Ryan to be around kids his age and as he was getting older. I wanted him to be around friends. He was getting old enough that he needed to be around friends."

When Ryan Carter was asked why he wanted to return to school, "To be with my brother (an older brother was attending school at the time) and have friends."

The Adams, who removed their two children because the teacher of their third grade daughter, Megan, and the mother "butted heads" returned their children so that Megan could have a certain teacher for fourth grade. Mrs. Adams suggested to her daughter, 'I said, 'Let's just try it, and I said you'll love [the teacher].' Megan always did love [the teacher]. [The teacher] has been wanting Megan since first grade. So she's [the teacher] been waiting all this time to get Megan."

Social relationships seem to be very important factor in making the decision to home school and in the decision to return the student to public school. Given the foregoing, for a home schooling student to successfully transition back into public education it seems that social relationships would play a key role.

Additionally, the idea that social relationships seem to have a large bearing on the success of the transition into public schools is born out when looking at the students after they returned to public schools. Each home schooled student had different experiences in social relationships in their transition to public school; therefore, their success varied. 
The middle school aged girl, Rebecca Bailey, who pleaded with her parents to let her return to public school, developed successful relationships with her teachers and her peers, even though at times it was a challenge. After three months in school, when asked to explain her social experiences in school, Rebecca Bailey stated, "It was kind of difficult. Some people remembered me and some didn't. A lot of my old friends were gone, so it was kind of difficult to figure out which I could fit with again but it's gone pretty smoothly."

Several months later, when Rebecca was asked the same question, she reiterated in more detail,

This has been the best year that I've ever had at school, I'm happy to say. I'm not in like the most popular peer group or anything but I've got a nice little circle of close friends. When I first came, people that I went to elementary school with, they remembered me and we talked but they had moved on with their own groups. That was kind of difficult to watch them and like be okay, I just need to find somebody that I can hang out with. For the first maybe six weeks at school, at lunch I would sit with everybody, I'd just switch tables everyday. I got worried around November that I had made a bad mistake coming back to public school for the social reason. I mean I had friends but nobody was really close at the time and I just started getting involved with more school activities and now I've got really, really good friends.

Rebecca Bailey also observed, "I was participating but not making very many friends, but I was hopeful. I had thought it would be really quick and easy.” Although 
this student found the process of making friends longer than anticipated, she was successful.

Her parent, Mrs. Bailey, agreed, “The encounters with the other kids were positive, the encounters with the teachers were positive, with the staff in the principal's office. Everything was very positive." The parent also observed, “There were almost no problems. All the things we worried about, none of them happened."

Rebecca Bailey's teachers viewed her very favorably and found that as Rebecca became more active in organizations, such as band, she became more confident. Rebecca explained,

People say that how I act now compared to how I acted at the very beginning of this year is like I'm not the same person and I said, 'Well I'm just comfortable and I am not afraid to act goofy.' I used to be a kid that just would sit down and I was really shy. I just needed to be myself, I guess, and let other people know what I thought of myself and to express myself.

One of Rebecca's teachers concluded, “She's a perfect kid, so mannerly and I appreciate that."

The Carters, who had home schooled their two boys, on and off, for four years continued to have problems with social relationships. One of the boys, David, only stayed in school for about two weeks. One of his teachers observed,

Well, see the other kids all came in here after being in the same room last year, so they were all in their own little world together and David was finding it hard to fit in. He was a little quieter than the other kids, 
not as rowdy, didn't want to push for what he wanted. So, David had a

little difficulty with moving into the school environment.

When the home schooled student, David, was asked what it was like returning to public school, he stated, "It was scary, kind of. Because I had never even saw the kids there before or the teachers."

In contrast, the mother, Mrs. Carter contended, "David immediately wanted to go back because he loves people and he does real good as far as the public goes." The parent removed David from school, after a very short period, due to a "personality conflict" with the teacher. Mrs. Carter stated, "I did not feel she [the teacher] was being fair to him [David]. If my boys are wrong, I will correct them but if they're not wrong, you treat them as well as you treat another child because if you don't, I will be all over you. That's just the way I am."

The second son, Ryan, continued to attend public school, although there were problems with social relationships, too. Ryan Carter did not know any of the other students in the classroom and asserted, "It is hardest getting to know people again."

Mrs. Carter considered Ryan the shier of the two children and noted, "He was home schooled longer because of his social problems." She also observed that the first few days of school went well,

Then Ryan started meeting these other kids, I don't know if it had anything to do with his home schooling or not but he was getting picked on over this and that. He got suspended four times this year because he's always had problems interacting with other kids, being comfortable around other kids because he is so shy. They decided 
they wanted to call him names and make fun of what he wore or just his hair, anything that they could make fun of him for. His grades were actually pretty good. They weren't terrible but they were decent, but Ryan's behavior was really hurting him academically and socially as well.

One of Ryan Carter's teachers explained, "I never did see him with other kids. He more or less stayed by himself. He had one seat and it was in the back of the room and I didn't see a lot of interaction but outside the classroom he had significant problems. He would end up in trouble, running his mouth and actually exploding his temper, physical aggression with other students." Another teacher agreed that Ryan had problems interacting in non-structured circumstances and stated, "It was when Ryan was out there on his own and had to deal with other kids on his own."

At the end of the first semester, when Ryan Carter was transferred to another school, the same scenario occurred. At first Ryan seemed to have no problems and the parent reported that her son felt like he was making friends. Mrs. Carter concluded, "When they [the students] don't fit in, they don't care about their grades or anything else. They start talking to more kids and becoming friends, things get better for them and they feel good about theirself [sic]. I love that for my son because he's needed that for a long time."

During this same time period, one of Ryan Carter's new teachers observed, "I've noticed that he's a very quiet kid. When it came time last week in Art class to choose a partner, he is very passive in waiting to be chosen and since the kids didn't know him that well, he wasn't chosen by anybody. It was like he didn't have the social skill 
that says, 'It's time to jump into the group." This same teacher concluded, "That is one thing that they [home schooled students] are going to lack is being more assertive because you have to be more assertive in a school situation than you do at home."

By May of that year, Mrs. Carter called me to report that she was removing Ryan from school due to social relationships. She contended that boys were starting to "pick on" Ryan; therefore, he would be home schooled again.

The Adams family that returned their middle school aged son, Evan, and fourth grade daughter, Megan, to public school did not seem to experience the problems with social relationships. The teachers reported that the children seemed to fit in right away and were very well received by the other students. One teacher stated, "Evan Adams has always been a very well-accepted kid in the group. He fit into these classrooms very naturally and very quickly." The student and parent concurred with this observation.

Mrs. Adams is the parent who brought her daughter in for a conference with the teacher before returning her to public school. The teacher made the following observation about that conference, "I was able to reassure Megan that she was ready to be in here and that she would blend right in. I was going to see that that would happen. I think they [Mrs. Adams and Megan] might have been a little afraid of the social aspect of it and I reassured them that I could handle that too."

However, by the end of the school year, Mrs. Adams said that her son, Evan, had asked about being home schooled again and she felt that his asking was connected to social relationships. At that time, the teachers also mentioned that they were having problems with a group of boys who were bullying others. The teachers, nor the 
parent, felt that Evan was a target of the group of boys. Nevertheless, Mrs. Adams explained, "You know you try to teach these kids to get along with everyone. I feel that's one reason that my son wants to be home schooled again, to get out of that situation because he can't understand and he can't accept what the other kids are doing---calling everyone names...”

\section{Support from public school teachers}

Each of the teachers involved with the study felt that initially home schooled students were hesitant to participate in the classroom activities and required support in this area. One middle school teacher stated, "Evan was rather timid about asking questions or telling me he didn't understand. Now, he's gotten out of that and he'll just say 'I don’t get it, help me.” David Carter's fifth grade teacher observed, “He wasn't the type to ask a lot of questions. That's what I couldn't get him to do. I said, 'If you don't understand, raise your hand and we'll straighten you out.' But he wasn't one to ask."

A middle school teacher explained that she could not get a response from Ryan Carter, even after putting him near her desk. The teacher stated, I told him, 'Anytime you have trouble, tell me.' I even wrote notes to mother requesting that Ryan come in before school, at lunch if he needed extra help, I would be glad to help him. He never asked for help. It was more like he either chose to do it or he didn't. That kind of thing, but he did need more assistance, whether he actually asked for it or not." 
The fourth grade teacher stated, "At first, Megan [Adams] was hesitant about answering, volunteering, that kind of stuff, but I don't see that at all now." The teacher further explained, "She [Megan] was reluctant to give answers, very insecure and wanted constant reassurance that she was doing it right. That's no longer happening but initially, the first half of the quarter, the first four weeks or so of school, there was a lot of reassurance needed."

A middle school teacher concluded, "I've noticed that they [returning home schooled students] like to be reassured. I notice them and they'll look around to see what the other children are doing. They've had one-on-one and when you throw them in a group of twenty-five, it's almost like they're real insecure for awhile."

Another teacher observed that home schooled students seemed to have trouble with group activities, "They [the home schooled students] were very individualized. They were real good to do individual assignments and projects, but when we would do any group activities, they didn't know how to share the knowledge or share the glory of their accomplishments." Several of the teachers felt that it took up to two or three months for the home school students to "get in the swing of things."

Mrs. Carter felt that the youngest of her sons, David, was not supported by the teacher. The parent stated, "I started my son back in public school the beginning of this year, but to be honest with you, his teacher was very...kind of like, I felt like she was biased because my son had been home schooled. She verbally made fun of some of his subjects and his abilities. She picked on him everyday.” Additionally, Mrs. Carter asserted that the teacher felt threatened professionally, "I feel as though she [the teacher] felt that her job was at risk and would some day in the future be as risk if 
more people start home schooling." As previously stated, the parent removed the student from public school due to this feeling of lack of support and "personality conflict" with the teacher, in addition to problems with his peers.

In contrast, Mrs. Bailey noted, "Having the one-on-one attention, she [Rebecca] missed it, but she made friendships with the teachers, almost all of them. She developed a relationship with them, she could talk to them." This same parent explained that she felt that home schooled students needed reinforcement or reassurance more than other children because they received it in their home school situation.

The support and encouragement from teachers also seemed to play a role in the successful transition to school. The teachers and parents seemed to recognize this phenomena. Two of the families, the Adams and the Baileys, felt that the teachers were supportive and sensitive to this need in the transition process.

When the home schooled students were asked if they felt like their public school teachers supported them when they returned to school, their feelings were mixed. Fourteen-year-old, Rebecca Bailey, described the experience, Mostly I came back here [the school] and the teachers said, 'Oh, you came from home schooling.' They ask me what it was like and that was basically it, they were kind of curious. They did not say, 'Well, did you cover this or do you think you need a little more help or do you think you're ahead of this class?' They didn't really focus on my curriculum from last year, it was more just, 'Did you enjoy it?' More of a personal thing. 
Although Rebecca said that she liked most all of her teachers, she reported needing more assistance in the transition to public school and stated, "They just treated me like any other student and in a way I wish they would have given me a little more support in the beginning because it was very hard to get back into the swing of it."

Other students did feel that their teachers gave them extra attention or help. The fourth grade student, Megan Adams, stated, "Well, she [the teacher] helped me on my comprehension because the other kids were like good at it and stuff. So she helped me on that." Megan Adams was the student that had the conference with the teacher before entering public school, and when asked if the teacher paid special attention to her since she had been home schooled, she replied, "Yes," however, she could not seem to put examples into words. Megan's middle school aged brother, Evan Adams, felt the same way. He believed that the teachers reviewed things with him as a way of paying more attention to him.

In the case of the two brothers, Ryan and David Carter, who returned, David staying only two weeks in public school, both the students voiced a dislike for their teachers. They did not feel that their teachers supported them in any way.

As previously stated, many of the teachers did not know initially that they had a student in their classroom who had been home schooled; therefore, it may have been difficult to offer any extra support to those students. The teacher that had the conference with the Mrs. Adams and Megan, before the child entered school, felt that she offered support to the student, and the student and parent agreed. 
One teacher, when asked ways they thought a home schooled student needed support when entering public school, stated, "Well, I think that we all need that. I mean, I try to give all my students emotional support. I'll do my best to take a compassionate view of things and help them [home schooled students] but if they don't reciprocate and at least show me, then I can't do [anything] if I don't know something is wrong."

There seems to be a lack of communication between the teacher, home schooled student and parent regarding the need for support from the teacher. Because a teacher does not know that they may have a home schooled student in their classroom, they cannot respond to needs. Additionally, there is a lack of communication from the student and the parent as to what those needs may be. In the one case where a conference did take place before the child entered school, the teacher appeared to be very aware of the need for support and responded to that need. Moreover, the student and the parent felt that the teacher offered the support that the returning home schooled student needed.

Other issues that were briefly mentioned as areas of difficulty by several parents and students included getting back into a real schedule or routine. Three of the students said that when they were home schooled that they were able to sleep in late and start their work later in the day. Parents also mentioned that it was difficult getting their child up and organized for the public school day. Additionally, parents felt that it was a difficult adjustment for their child to be on a schedule throughout the school day. 
One parent, Mrs. Bailey, said that when her daughter, Rebecca, first returned to public school that she was exhausted and explained, "Part of it was getting up, getting ready and going all day. It exhausted her [Rebecca] because we would get up and just lounge about and read and talk about the lessons." Mrs. Bailey concluded, "I think getting back into the swing of the daily grind was the hardest because at home if she [Rebecca] took a little longer with something, that was okay. When she got back to school, she had to keep up with the class, turn things in on time. It was kind of stressful for the first month or six weeks or so..." Another parent, Mrs. Carter, also voiced the same concern, "Getting back into the schedule you [the schools] have and not being able to freely go to the bathroom anytime you want or whatever. Also, the emotional stress that I find in that home schooled [students] work slower and in school they are timed to get things all packed in."

One middle school teacher recognized the issue of time constraints as an area of concern. She explained, "It's according to the child, but I have found with children that have been home schooled, they have no understanding of time constraints. I suppose it's because they work at their own speed. [In school,] because things are timed, you go by a schedule, so scheduling is real difficult for students who have been home schooled."

This kind of time adjustment was not mentioned by the other public school teachers. Making teachers aware of the adjustments that home schooled students are facing, especially in the area of time constraints, may give them a better understanding of the home schooled student; therefore, affecting the transition of the home schooled student to public school. Teachers may better be able to support 
returning home schooled students by offering flexibility of time on assignments throughout the transitional period.

One of the students and parents, Mrs. Bailey and Rebecca, suggested that a support group for returning home schooled students would be beneficial. When Rebecca was asked is she needed emotional support when she returned to public school, she replied, "It would have been nice... They [the school] should probably have like a club or some type of a gathering for students who have just started to school or are returning from home schooling to public school, or from private school or whatever."

When asked to describe what the group would be like, Rebecca Bailey suggested, "I would want there to be like several adults there and basically just talk it out; like how you think your classes are going, if you've met any new people. And even if you don't make friends with other students that you just have met, you have this group and they are probably feeling the same emotions that you are."

The parent, Mrs. Bailey, agreed and felt that it would be beneficial for the students to talk about the experience and any problems that were occurring. Mrs. Bailey observed, "I think that would be good. In fact, she [Rebecca] found another kid that had been home schooled and they sort of compare notes and it helped her."

\section{Academic experiences in the transition}

All the home schooled students interviewed experienced some anxiety about how they would measure up academically. Of the five students that returned to public school, four of them felt that public school was more difficult. Two of the mothers, Mrs. Adams and Mrs. Carter, also expressed concerns about their children's academic 
abilities. The teachers of four of the students felt that they were behind academically, while the teachers of the other student, Rebecca Bailey, felt that she was ahead academically.

Rebecca Bailey, the middle school female, was anxious to know if she was going to "measure up" academically. Her mother explained, "The anxiety about that was the hardest part for Rebecca. Wondering if she could make the grade, you know. If she could get back in and be able to do the work." In contrast, the parent did not feel like this would be a problem. Throughout the home school experience the parent had followed the public school curriculum and felt that they were able to cover more material than the public school.

This home schooled student's teachers agreed with her mother, Mrs. Bailey. One teacher stated, "The thing that I think surprised me when I found out she [Rebecca] had been home schooled was that she was one of the few kids that I have in regular English classes that was far ahead of everyone else. Rebecca's just exceptional with everything she does." Rebecca Bailey's other teachers agreed that she was an excellent student and wanted to move her from regular classes to honors classes.

The family that returned both their son and daughter to public school were also anxious about what level the students would be on academically. Mrs. Adams felt her daughter also shared her concerns and stated, "She [Megan] was afraid that she would disappoint the teacher or not be good enough in her math and comprehension." Mrs. Adams worried that her daughter's "reading comprehension skills were poor."

During the conference between the parent and teacher, before Megan entered school, these issues were discussed. The teacher explained, "I assured her Mom that I 
knew how to teach a child to improve their comprehension, there were strategies, and so forth, you teach in reading." The teacher did feel that the student was a little behind in some areas, but felt the student improved throughout the school year and with that improvement the student's confidence grew; thus, the student became less anxious.

Evan Adams also felt that he was behind in some areas and voiced a concern, although the parent seemed less concerned about him academically, than the daughter. Three of his middle school teachers felt that he was "a little behind academically" while two of them felt that he was on level.

Evan's sixth math teacher stated, "It's a little bit harder for him to catch on to new skills. He's still not sure of himself, particularly in the areas of basic multiplication and division by two or more digits. He doesn't have his basic facts down pat." Evan's social studies teacher said, "Basically this child, especially in the area of comprehension, was extremely weak. He could not seem to follow directions...I don't attribute all of that to home schooling, but I'm sure it was a factor somewhat."

It should be noted that Mrs. Adams used the public school textbooks in some subjects, but used other materials that she had purchased in other subjects. Additionally, Mrs. Adams used other material as supplements to the county textbooks.

The Carter family, that returned their two sons to public school, stated that the boys were behind when they began to home school them and felt that they could learn more while being home schooled. Mrs. Carter stated, "I think scholastically it's better 
on them...I can teach them as well as anyone else can and they can absorb more when I teach them because it's one-to-one"

In contrast, Mrs. Carter also stated, I probably should have pushed him [Ryan] a little harder in math...I probably wish that I had spent more time with his math. I probably didn't go into as much detail as I probably should have or spent as long a period of time on it as I should have. David, I should have pushed him harder with his cursive writing, but you know you don't have to write in cursive and I don't push as hard on that.

Mrs. Carter further explained, "The main thing that I pushed them on is [sic] their English and their reading and their history and their math, but I should have pushed Ryan harder on math when I first started home schooling him, but I didn't."

All of the teachers who had Ryan and David in their classrooms felt that they were behind academically. The teacher of David, who only stayed in public school for two weeks, stated, "I think she [Mrs. Carter] was upset with me because I gave David homework each night to try and get him to catch up and learn some very simple things that he hadn't learned last year. Mrs. Carter was very upset with me. David hadn't learned to write a correct sentence yet and couldn't get his thoughts down on paper." The teacher continued, "I asked her to work with him at home because he was a little bit behind the rest of the class. Mrs. Carter was terribly upset. The mother felt 'He couldn't be behind, I did my job last year."' 
Regarding the older son, Ryan Carter, the sixth grade teachers said that he needed more one-to-one assistance and had trouble competing assignments independently. One of the middle school teachers explained,

Ryan was very weak in basic math skills, computation, very, very weak. In some areas he seemed to have more general knowledge about some things. It's hard to pinpoint but in some areas he might have known more about things, but as far as skills and being on level with other students, he wasn't."

Generally, two of the families experiences difficulty in the area of academics in the transition from home school to public school. The experience for the student whose parent and teacher held a conference before the child enter school, seemed to be smoother. Even though the student was having difficulty in some areas, which the parent, student, and teacher agreed upon, those needs were addressed in the conference. Because the teacher was made aware of the area of concern, she was able to address the areas of difficulty from the first day of school.

One family seemed to have an adversarial relationship with the teachers in regard to what was taught in the home school experience. Instead of working together to solve the problem, there seemed to be a defensiveness on the part of the mother.

\section{Dual enrollment in public school and home school}

While discussing the need for a conference before the child enters school, one teacher suggested that the student should, "...go to school and visit for a few hours, go to a classroom and see how things operate so the child would have a general idea of what to expect when they come back to school after having been home schooled." 
Another teacher suggested, “...maybe just let the kid come and have lunch with them [the other students] one day or two, just a few little activities---make it gradual."

While the state law does provide for dual enrollment with the approval of the local Board of Education, the county in which the study took place, opts not to allow part time attendance. However, the system must provide special education services for home schooled children. One teacher addressed the attendance of a home schooled student in the county gifted program based upon a situation that had occurred several years ago. The teacher explained,

He [the home schooled student] was only here part of the day because he was involved in the gifted program. His mother would bring him and he was placed in my home room for twenty minutes or until he left to go to the gifted classroom. Well, after he was in my classroom for about six weeks, he asked his Mom to come to public school.

The returning home schooling students took this concept one step further. Several of the students thought that attending public school part time was something that they would be interested in doing on a permanent basis. When the students were asked if they would like to be home schooled part of the day and attend public school part of the day, they all replied, "Yes." Middle school student, Rebecca Bailey stated, The core classes, I would want to take at home so I could go at my own pace and review things that I needed to. Things like computer, I would take at school because you get to learn more, it teaches you how to use programs and everything is really up-to-date. Anything like 
art or an elective and special classes, I would take at [public] school.

Mrs. Bailey explained, “The concept [dual enrollment] is a good one, and should probably be offered routinely to home schooled students. Obviously, the variety of labs, adult role models, social and intellectual interaction of public school cannot be approximated at home."

Another parent thought that to "ease the students in gradually" would be a good idea. Mrs. Carter concluded,

They [the student] would still have an outside life, more or less. Also, they'd still have friends. The things the parents are lacking in the studies, maybe the school could make up on that end. The parents can give them [the student] one-to-one when they are at home. The parents can give them more time with their lessons than what a teacher can because she can't devote all her time to one student.

Student, Rebecca Bailey stated, "I think everybody should take the core classes at home because those are the ones needed to basically survive, and anything like labs or computer courses or electives should be taken at a school. I think that would be good for everybody, not just having public schooling where you take everything."

Easing the home schooled student back into public school seems to be an idea that was embraced by teachers, students and parents. Additionally, the option of attending public school on a part time basis while being home schooled is something that students and parents would consider as an alternative to fulltime home schooling. 


\section{Communications throughout the home schooling experience}

An issue that emerged throughout the study was that of communication between the school and home school parents. Some educators and parents felt that there should be open lines of communication during the time that the home schooling was taking place. It was suggested by both groups that there should be a person at the central office of board of education to act as a liaison for home schooling parents. Parents and teachers believed that parents needed to be familiar with the school's curriculum because it would ultimately make the transition back to public schools smoother.

Mrs. Bailey stated, "When we first started, I had no idea what I was doing. It would have been helpful to talk to someone at that time, I think, during that initial start-up time because you really need some information." In a second interview she confirmed her beginning feelings of insecurity with home schooling, "You're a mommy one day and the next you're a teacher. It was hard and it was scary." Mrs. Bailey wrote a letter as a follow up to one interview and stated, "A permanent liaison between the board and the home school families may be too much to ask. Just making yourselves available in a comfortable setting on occasion would probably be appreciated and could enhance cooperation and understanding."

Mrs. Adams also stated that she would liked to have had communication with a school representative during the home schooling period of time, "I wish I could have gone to the school board and said, 'Okay, what do I need to do or what I can I use to keep them [Megan and Evan] up with the school system?" She further explained, "I had to read and make up my own tests and everything--questions and study things. I had to do everything. I had to learn everything myself." 
All three of the home schooling parents expressed the need for communication. Mrs. Carter said, "I think that it would be an excellent idea to have a few guidelines. For example, I was not sure how long to spend on a lesson." In another interview she stated, "It would help the parents to make sure they were keeping up with the public school. Then if they [the students] returned, they would be in the same place as the children in public school." Mrs. Carter also believed that home schooling parents should be required to submit samples of the student's work to school personnel throughout the home schooling time. Mrs. Carter stated,

I think that any child that has been home schooled, it should be mandatory that they have to submit their progress more often than what they do. I would even say as much as once a month, it should submitted to a classroom teacher to see if they are on track instead of doing a portfolio or taking a SAT. I will be honest with you, when I first started, sometimes I'd find myself feeling like I was running in circles. I don't think that that would be a bad idea for it to be mandatory that you submit what the child has done.

Educators also recognized the benefit of communicating with home school families while the students were out of the public school. One teacher observed, "I know we may not, as educators, want to encourage home schooling, but if it is being done, then we need to do everything we can do to prepare them for the future." This same educator suggested that home schooling parents participate in public school curriculum teams. He stated,

When we set up curriculum, the teams to develop the curriculum 
program that we're using within our schools, I think we should have parent input from these people that are involved in home schooling. And I'd like to know what we are not doing within our school system that they feel we need to be trying and vice versa, we could talk about what they are doing. I feel that needs to be addressed.

A middle school teacher explained, "If parents would know more about the public schools, what we taught - the school curriculum, what is offered, I feel like that would make a big difference in helping their child adjust when returning to the public school system." One fourth grade teacher stated, "I think parents need support. They need someone to go to and say, 'Am I doing this right?'” Another teacher believed that open lines of communication may assist parents and stated, "Maybe they [the parents] could get help first in the areas they feel weak in before they would actually be teaching their child."

To assist in making the transition into public schools easier for parents, students and teachers, many of those interviewed believed that communication throughout the home schooling experience was a factor. Parents and educators identified the need for communication, particularly regarding curriculum, as important.

Chapter IV investigated the results of the survey and the information gathered in the in-depth interviews. As a result of that investigation, seven emergent issues were identified. The information provided in Chapter IV will provide the framework for Chapters V and VI. 


\section{Chapter V}

\section{Researcher's Focus on Findings}

The focus of Chapter V is twofold: 1) the discussion of what I believed to be important issues in Chapter IV and 2) what I discovered and learned by conducting the interviews with home schooling families and the public school educators of those returning home schooling students.

This study was designed to investigate the reasons why home schooling families choose to enter or reenter their children in the public school system and the critical issues embedded in the transition from home schooling to public schools. Of course, with the completion of an in-depth review of the literature in this area and preconceived personal beliefs because of the my professional contact with home schooling families, there was a certain amount of background knowledge that I began the observations and interviews. However, upon the completion of the two rounds of interviews, there were many factors that emerged with no forewarning and I was not prepared for the revelations.

These discoveries were important for several reasons. The most apparent of these reasons was that the "new issues" that emerged were not cited in research; therefore, they are prime targets for further research and investigation. Some of the issues do appear in other studies, but emerge in this study with different characteristics and scope. Other issues which I believed would emerge, due to past information, did not. Again, these omissions were enlightening.

Three issues which did not emerge in the in-depth interviews which research indicated would were: 1) religious reason for home schooling; 2) curriculum used by 
home schooling families which included the teaching of "values" and 3) home schooling parents developing their own curriculum.

Although the survey conducted in this study and past research indicated that religious reasons was the number one issue that persuaded a family to home school, none of the participants in the interviews sighted this their impetus. One mother did state the she "ask God for guidance" in making the decision to return her children to public school; however, she did not indicate that religious reasons were what prompted her to initiate home schooling.

Breshears found in a 1996 study that the curricular materials selected reinforced the values of the families; however, none of the families interviewed spoke of wanting to connote family values to their children. All of the families selected to use the county textbooks. The families did not add family values to the curriculum in an overt fashion.

Lines (1987) found that fifty to seventy-five percent of the home schooling parents designed their own curricula rather than use the services or materials from institutions. Again, the families interviewed selected to use the county textbooks. The parents interviewed indicated that they felt that it was important that their children study the same curriculum that their children's public school counterpart was being exposed to throughout the school year.

The omission of the aforementioned issues was surprising. Although the sampling of three families was admittedly small, the families seemed to be very diverse. It made me question the make up of home schooling families as I had thought of from past research and limited interactions. Perhaps the home schooling families were not 
the "mavericks" that I had pictured, but parents who wanted their children to have the same curriculum that public school children were receiving.

Additionally, the emergent issues, or in some cases non-issues, were important because of the type of research from which they resulted. I believe that some of the issues would not have emerged with such clarity in quantitative research as they did with qualitative research. Because of the opportunity to delve into components with the interviewee and one-to-one, eye-to-eye contact, the information gathered had a clarity which may not have been achieved through surveys.

For example, Mrs. Bailey indicated on the survey that she had removed her daughter, Rebecca, from public school for safety reasons; however, in the in-depth interview it was discovered that the root of the reason was different. In the first interview Mrs. Bailey stated, “The middle school was a very difficult transition for her [Rebecca]. Going in the sixth grade, she was a little kid, she was terrified and a lot of the children, probably who had been held back and were quite a bit older, they were in her class." Rebecca admitted that she did not know how to handle the new situation. Furthermore, in a letter received from Mrs. Bailey after the first interview, she conveyed that dual enrollment, during the semester before Rebecca was removed from public school, would have been an alternative to complete removal. If safety were the real issue, dual enrollment in public school and home school would not seem to be a viable solution.

The nature of qualitative research was valuable in gathering information in this study. The in-depth interviews allowed for clarification of issues and provided for delving into answers given by the participants. 
The following five areas are discussed from the perspective of the importance and scope of the issue and their originality me:

- social issues as a reason to remove or return a student to public schools;

- communication throughout the home schooling and entering experience;

- dual enrollment in public school and home school;

- lack of understanding between public educators and home schooling families and

- omission of the issues of discipline and technology curriculum.

\section{Social issues as a reason to remove or return a student to public schools}

In the review of literature regarding home schooling, the majority of the research pointed to religious purposes as the main reason families selected to home school their children. Although in a 1996 study of Iowa home schoolers, Dahm reported that religion was only one of many reasons. Other reasons for home schooling included student safety, societal influences, such as drugs, increased individualization of instruction and philosophical differences in education.

Throughout the review of literature, various reasons were given for families choosing to home school their children; however, the reason of social relationships was never cited. Additionally, the information I gathered through surveys also confirmed that religious issues were the primary reason for home schooling.

One of the initial questions on the first interview guide asked parents why they decided to home school their child(ren)? Given the foregoing, I expected to receive a 
response that centered around a religious concern; however, in every case parents cited social relationships as the main reason they selected to home school. Two of the families told stories about how their child was finding it difficult to get along with other students. Both explanations began with their child being "bullied," although after further discussion the parents also stated that their child did not seem socially equipped to handle the situation. In the third family, the child was having a difficult time "getting along with" the teacher and, subsequently, the parent also "butted heads" with the teacher.

At that point the research looked at the survey information with "new eyes." By combining the reasons of socialization, bullying in school and inability of the students to cope, a significant number is accumulated. Could all of these responses have to do with social relationships? The answer will not be discovered in this research because all of the families were not interviewed, so the real intent or root of their answer is unknown.

In addition, all three families participating in the study decided to return their child(ren) to public school because of social relationships. In one case, the child asked to return to public school so that they could be with friends. In another family, the parent felt that it was important for her sons to be around "friends." However, eventually, both of the children returned to home schooling because they were being "picked on" and could not cope socially. In the third family, the student was returned because of a relationship between the teacher and the family. The family viewed the educator as "good" and wanted their daughter to be in that classroom. 
It was a very perplexing finding that social relationships played such an important role in the home schooling decision. The nature of the qualitative research assist in uncovering this fact. By listening to the stories of the parents and asking questions, I believe information was revealed that may not have been initially apparent.

\section{Communication throughout the home schooling and entering experience}

Educators and home schooling parents both voiced the need for communication and cooperation throughout the home schooling experience. Because of my experiences as home school coordinator for the school district, it was believed that home schooling families wanted to be left alone without interference from the public school system.

Often times when I requested information from the home school families, the response was received from the Home School Association attorney rather than the family. The attorney would state that the family was not required by law to give that information to the board of education. For example, often times additional information was requested, as a clarification, regarding the plan of instruction or curriculum to be used. Because of the response received in several cases from the attorney, I believed that the home schooling families did not want interference nor assistance from the public school system.

In contrast, the parents participating in the study talked about the feeling of insecurity in home schooling, particularly in the initial stages. They talked about the need for an exchange of information between the board of education and home schooling families. All of the families felt that if the lines of communication and cooperation were kept open throughout the home school experience, then students, 
parents and educators would have a better transition experience. Moreover, parents believed that communication throughout the home schooling period, would help to assure that the home schooled student to return to public school covering the same amount of material and concepts as the public school students.

Although not as prevalent, some of the educators also perceived the need for open lines of communication between home schooling families and the school system. Teachers cited open lines of communication as a way to assure that the home schooling student would receive the best possible education and, again, cover the same concepts and amount of material as their public school peers.

The public school system and the home schooling families, although weary of one another, both realized the need and benefits of communication throughout the home schooling experience. Everyone involved believed that the children would be able to make a smoother transition back into public schools if open lines of communication were established.

\section{Dual enrollment in public school and home school basis}

Parents and students interviewed asserted that dual enrollment would be a beneficial arrangement. And although this adaptation is provided for in the law with board of education approval, the school district in which the study was conducted has selected not to allow part time attendance. Again, I was surprised by the home schooling families' eagerness to work with the school system in educating their children.

In the initial review of literature, very little information was found concerning partnerships between school systems and home schooling families. However, in more 
recent literature, the topic has become more prevalent. In a 1999 Association for Supervision and Curriculum Development (ASCD) article, the benefits of collaboration for public schools and home schooled students were discussed. The author recognized the innate distrust and tension that exists between school-based educators and home schooling parents, in some cases. Although other home schooling parents asserted that communication is the key to successful partnerships and one stated,

There are a lot of paranoid home schoolers who think the school system is evil and doesn't meet their kids' needs. On the other hand, there are educators who stereotype home schoolers as wacko and more who think that home schooling is inadequate. But the more exposure [proponents of each method] have to the other, the more likely mutual respect will develop (Rasmussen, 5).

Rasmussen observed, “At first glance, advantages of homeschool-school partnerships may appear to be one-sided, with resources and services going to home schoolers" $(1999,4)$. However, there are critical reasons for schools to work with home schoolers. In many states, it is the law. In the school district where this study took place, home schoolers are serviced for any special education needs, i.e., speech, gifted, learning disability, etc., but are not allowed to attend regular education classes on a part time basis.

On a practical level, public schools do receive state funding for those children who do attend only portions of the school day. This study's school district was reimbursed by dividing the day into sevenths. The school district would be allowed funding for 
any portion of the day in which the student attends. Moreover, home schooling parents are tax payers and residents of communities, and there are certain rights that they are afforded.

The primary reason to allow home schoolers to have dual enrollment was voiced by an assistant superintendent in Battle Ground, Washington, "We need to work together-parents, the community, the public school, the government. We're all in this together" (Rasmussen 1999, 5) A home schooling parent reiterated this sentiment, "The bottom line, schools and parents have a common interest: the child is the reason they are all there" (Rasmussen 1999, 5).

The impact of dual enrollment of home schoolers would be beneficial in a full time transition back to public schools. Students would already be familiar with the daily routines, discipline requirements and the school staff. Dual enrollment, although not an option for parents in this district, should be explored.

\section{Lack of Understanding between public educators and home schooling families}

Given the foregoing, it would seem apparent that there was a lack of understanding between public educators and home schooling families. I was confounded by the depth of the lack of understanding and believed this issue to be pivotal for a successful transition.

Home schooling families repeatedly stated in the interviews that they wanted public educators to have a better understanding of their choice to home school. Studies do show that home schooled children do learn, and often outperform their publicly and privately schooled peers on standardized exams. A recent Time magazine article stated, "This year homeschoolers scored an average of 1,100 on the 
SAT — a full 81 points above the national average—and 22.8 on the ACT, compared with the national average of 21 (Winters 2000,55).”

In contrast, often times public school educators believe that home schooled students are being shortchanged academically. Throughout the interviews conducted for this study, the public school educators stated that they did not believe that parents could meet all the academic needs of the students.

Additionally, public school educators also voiced concern regarding the socialization of the home schooled student. This concern has also been reputed by research. Many home schooling families provide socialization for their children through community sports activities, as confirmed in the interviews. Many families participate in home school association activities for their children, which provided for socialization. Other activity which home schooling families participated in were church events, which provided social interaction for the children.

When interviewing public school educators for the study, teachers seemed to have a general negative feeling towards home schooling; however, when discussing a specific child there seemed to be a much more positive attitude. One parent who was interviewed felt that teachers had a negative attitude because they felt that their jobs were being threatened by the people that choose to home school. Rusmussen found that for many parents, choosing to home school does not necessarily mean that they disapprove of public schools. "Many home schooling parents insist that they have opted out of full-time school because they can better meet their children's needs on a one-on-one basis. But they remain supportive of schools and their services," Rusmussen stated $(1999,4)$. 
Several of the teachers also said that they would like to know more about home schooling, but not in a general aspect. The educators were more concerned with the curriculum, what materials were used, the amount of material covered and what learning strategies were employed by each home schooling family.

Because I was an employee of the board of education who dealt with home schooling, the perspective was from this stance. In most cases, I believed that the child would be better served in public schools for a variety of reasons. However, after interviewing families that have selected to home school, that belief has been altered.

By interfacing directly, exchanging ideas, and having in-depth conversations, the sincerity of the home schooling family came to light. The parents were able to articulate their child's individual needs, strengths and weaknesses and their belief that they could better address these needs more fully in a one-to-one situation. The parents also spoke about the intimacy of the process and the ability to really connect and get to know their child in the home schooling atmosphere. For public school educators and this researcher, there may be things to learn from the home schooling parent.

\section{Omission of the issues of discipline and technology}

Sometimes the omission of certain components can be very revealing. On the initial interview guides there were questions regarding discipline and the use of technology in the home. When these topics were discussed, they were not seen as problems or areas of concern for public school educators, parents or students in most situations.

As supported by the surveys and in the interviews, most of the students were using some technology in the homes as a way to receive the curriculum. I believed that the 
public schools would offer more availability to the latest technology and better programs. This belief stemmed from the amount of money that the school system had invested in hardware, software programs and teacher training. However, there did not seem to be the gap anticipated in the area of technology.

After consideration and review of the information gathered, I believed that this phenomena may be due to the fact that the public schools are not utilizing the technology available to its fullest potential. Additionally, the technology available is not being used consistently in the public schools. Whatever the case, a gap between the home schoolers and the public school students' knowledge and use of technology did not seem to exist.

The area of discipline also seems to be a non-issue in the transition of the home schooling student into public schools. I believed that home schooled students may have had difficulty when faced with rules and regulations with which they were unfamiliar. Moreover, the home schooled students were accustomed to a certain amount of freedom and flexibility when working in a one-to-one situation; thus, the students were not accustomed to following rules oriented to a group situation.

In contrast, given the perception, the public school teachers did not view home schooled students as having a problem in the area of discipline. In fact, most of the teachers said that home schooled were "very polite, quite and reserved." The two Carter children did have some trouble in school, but this difficulty did not stem from classroom discipline situations, rather from social situations outside of the classroom.

Little literature had been found to make me believe that discipline would be an issue; however, from my own background, discipline did seem to be a factor. Many 
times when parents called to inquire about home schooling, there would be an issue at the root of the inquiry regarding treatment by a teacher to the student. With this personal background knowledge, there was reason to suspect that discipline may have been an issue. Therefore, I was surprised by the finding that discipline was not a concern in the transition process for anyone-teachers, parents or students.

The aforementioned were issues which I found perplexing or were "new issues" when considering the review of literature. It is my belief that some or all of these components may not have been revealed through quantitative research; therefore, it necessitated the use of qualitative research to reveal the embedded information regarding the issues surrounding the transition of home schooled children into public schools. Having examined and noted these issues, they now serve as support for Chapter VI, "Summary, Conclusions and Recommendations." 


\section{Chapter VI}

Summary, Conclusions, Implications and Future Research

\section{Summary}

The objective of this study was to investigate the issues embedded in the transition of home schooled students entering or reentering public school. The research was approached primarily from a qualitative stance, however, quantitative research was also employed.

An initial survey was distributed to all home schooling families in the school district, which mainly explored the demographics of the home schooling families. The response rate was $28.81 \%$. The scope of the survey included the education level of the parents, their past experiences with home schooling, occupations and the families' affiliation with home school associations. Other questions on the survey investigated the reason the families choose to home school and when, if and why they would chose to return their child(ren) to public school.

Three families who selected to enter their child(ren) in public school agreed to be part of in-depth interviews. The public school teachers who had the children of the families placed in their classrooms were also interviewed. Two rounds of interviews were conducted over a period of eight months. Interview guides were used to direct the questioning, however, the conversations were also allowed to evolve according to the issues introduced by the interviewees. The initial guides were developed as a result of the posed research questions, review of literature and the results of the surveys. Forty-three interviews were conducted in total, all of which were audio 
taped and transcribed. The information was then coded and compartmentalized into themes or issues.

The emergent themes or issues were common among all those that were interviewed and were the key components in addressing the original research questions. However, there were emergent issues that developed independently of the research questions, and were compelling components of this research. The following emergent issues are addressed in the "Conclusions" portion of this chapter:

- The importance of conferences among parents, students and educators before the student returns to public school;

- the viewing of "parents as teachers" and the attitude of public teachers toward home schooling;

- the importance of the home schooled student entering public school to establish social relationships with peers and adults;

- support that is needed from the public school teachers;

- academic experiences in the transition;

- the advantages dual enrollment, attending public school on a part time basis for a limited transition time or as an unlimited educational choice and

- open communications between families and public schools throughout the home schooling experience.

Although there were common themes or issues that did emerge, it should also be noted that the home school families that took part in the study were also very diverse. For example, while all of the families began home schooling due to social issues, 
there were also other contributing factors that were particular to each family. As with most decisions, there are multiple pros and cons that are considered.

The compelling issue to home school for the Adams' Family was a negative relationship with one of their children's teachers. However, the mother also felt strongly that it was ultimately the parent's "responsibility" to educate their children. Mrs. Adams also believed that she could offer her children a better education in many areas in a "one-to-one" situation. Further, Mrs. Adams spoke of asking "God for guidance" in making the decision to return her children to public school.

Likewise, the other two families considered more than one reason when making the decision to home school their children. These reasons included meeting their child's individual needs, allowing time for the child to mature and establishing a more intimate relationship with the child.

The three home schooling families also varied in their educational backgrounds, occupations, relationships with the public school system, number of children in the family, approach to the curriculum and length of time that they selected to home school their children.

In the same vein, the educators that took part in the study were a very diverse group. Each teacher came to the study with varied past experiences with home schooled children and with their own preconceived ideas regarding home schooling. Likewise, because they were being questioned about their experiences regarding one particular student, their reactions and comments must be viewed accordingly.

Regardless of the diversity and differences among the home schooling families and the educators, there were prevailing common issues that did emerge. Those issues and 
their relationship, or lack of relationship, to the research questions were the basis for the conclusions drawn in this study.

\section{Conclusions}

The survey was a precursor to the interviews. Only the parents were surveyed for background information. Seventeen families returned the survey for a response rate of 28.81 percent. The families had a total of 35 children in grade kindergarten through eleventh grade. Because the study is qualitative in nature, the survey was never intended to be a substantial part of the study. However, it does provide valuable background information regarding demographics and some insight into why families home school and why families choose to return their children to public education.

The survey supported the theory that the home schooling families were diverse. While the answers to the demographic questions can easily be averaged, the questions that required narrative answers revealed much more information about the individual families.

The survey results found that families had home schooled children for a total of 139 years, with the average number of years being 3.97. Eighteen of the students had been enrolled in public schools at some point in their educational careers, while 17 of the students had been home schooled for their entire educations. The average grade level of the student was 5.42. There were 18 female students and 12 male students represented, however, the sex was not given for five of the students.

The mother's education level varied from a GED to a Master's Degree, with the average being approximately two years of some sort of higher education. The father's education level covered a more extreme range, from less than twelve years to a 
Doctoral Degree. Again, the average level of education for the fathers was approximately two years of higher education.

While fifteen of the parents indicated that they had not been home schooled, one parent had been home schooled and attended public school during her educational career. Twelve of the families indicated that no one else in their families had been home schooled, whereas, four responded that someone in their extended family had had a home schooling experience.

The occupations of the parents differed vastly. The most common occupation was housewife or homemaker, with eight parents indicating this area. Three of the parents shared the occupation of nursing. Additionally, three other parents were employed in the medical field, one as a pharmacist, one as a doctor and one was not specific, indicated only "professional medical field." Occupations that were common to two parents were teacher and minister. Additionally, two of the parents were disabled.

Fifteen of the families indicated that there was a computer in the home, while only one did not have a computer. Thirteen of the families used the computer to deliver instruction for the student, while only one family reported that they did not use it for instruction.

Twelve of the families belonged to a home school association. (This information indicated that the chances that I would interview a family that participated in a home school association were great. However, none of the families interviewed were associated with an organized group for home schooling.)

The reasons given as to why families first choose to home school their child(ren) varied substantially. The most frequent reason given had to do with religious issues. 
Seven families cited religious issues as one reason or the only reason that they home schooled. Of the seven families citing religious issues, three of them had always home schooled their children, while four families had children that had been enrolled in public education before they decided to home school.

The next two most frequently given reasons were safety of child(ren) and the belief that a better education could be provided at home. Five families cited safety issues and six families believed that they could provide a better education at home as the reason that they began to home school their child(ren).

Other reasons that two families indicated were 1) control of behavior/control of discipline, 2) socialization, 3) bullying in school, 4) individual attention and 5) treatment by teacher/uncaring school system.

All of the other reasons given as to why the families began to home school were only mentioned by one of the families. However, there are several reasons given that could be combined, i.e., socialization, bullying in school and student unable to cope. Although it is difficult to know decisively if the responders would agree that these categories were common ones, if combined the responses would total five.

It should be noted that the question which targeted the "reasons parents select to home school their children" ask for a narrative answer; therefore, multiple reasons could be given. As the research indicated, the reasons that motivate families to home school their children were widespread. Nevertheless, religious reasons was the most common answer, again just as research noted.

Three of the families had preschoolers in their homes and two of the families planned to home school those children, also. Three of the families planned to enter or 
reenter their children in public school in the future, one family planned to enter their child in a Christian school and two of the families were undecided. Of the three families who planned to enroll their children in public school, two of the families indicated that they would do so in the ninth grade and one in the fourth grade.

Seven families responded to the question, "If you have chosen to return or plan to return your child(ren) to public school, describe the reason(s) for that decision." Again, a narrative response was required, so more than one reason could be given per family. The only response that the families had in common was to provide socialization and interaction with peers, with two of the families indicating this reason. The other reasons given were: 1) would return if Bible were taught in public school, 2) burnout of the parents as the teacher of the child(ren), 3) exposure to other ideas, 4) to enroll in a specific classroom to be taught by a specific teacher, 5) attain a high school diploma and 6) the parent did not meet the minimum state requirements to teach the student at home.

The survey served to give a "flavor" for the diversity of the home schooling families. Because of the low return rate it is difficult to determine if this is representative of the majority of the home schooling families in the district; however, the data collect did support and confirm that of pervious studies in this area.

The low return rate in and of itself may be the most revealing element of the survey. Home schoolers sometimes view the public school system with wariness; therefore, they do not seek out nor want contact with someone who is associated with that system. However, the returned surveys did assist in the background information 
for the interview guides and the interviews themselves, which were the crux of the study. Those interviews were the basis for the remainder of the chapter.

The conclusions in this chapter are presented by correlating six of the seven emergent issues with the research questions to answer those questions. The seventh emergent issue was addressed as a separate topic, not directly correlated to the research questions. Each of the research questions will be addressed separately, although some of the emergent issues did overlap into several of the questions. The following outline of the research questions and the correlating emergent issues was designed to assist the reader in establishing an overview of the conclusions:

1) What are the factors that influence the home schooling family's (parents'/guardians') decision to enroll or re-enroll their child(ren) in public schools?

- the importance of the home schooled student entering public school to establish social relationships with peers and adults

2) What do home schooling guardians or families, who choose to enter or re-enter their children in public schools, believe public schools currently do and/or should do to support their children in their transition from home to school?

- open communications between families and public schools throughout the home schooling experience

- $\quad$ support that is needed from the public school teachers

3) What is the experience that home schooling students have upon entering or reentering public schools and what could the public schools do to participate in that experience? What is the role of the public school in that experience? 
- the viewing of "parents as teachers" and the attitude of public teachers toward home schooling;

4) What are the critical issues embedded in the transition from home schooling to public schools for guardians/parent, children and educators?

- the importance of conferences among parents, students and educators before the student returns to public school

- the importance of the home schooled student entering public school to establish social relationships with peers and adults

The seventh emergent issue, dual attendance for home schooled students, for a limited transition time or as an unlimited educational choice, is presented as a separate issue.

\section{Research Question \#1: What are the factors that influence the home schooling} family's (parents'/guardians') decision to enroll or re-enroll their child(ren) in public $\underline{\text { schools? }}$

The answer to the question was clearly articulated by the parents and students participating in the study: social relationships were the driving force behind the decision to enroll home schooled students into public schools. As previously stated, the irony of the impetus to return to public schools was that it was the same reason that the three families removed their child(ren) from public school. The survey also indicated that children returned to public schools to establish peer interaction.

The Adams Family, who had removed their two children from public school because of a negative relationship with a teacher, similarly returned the children to public school so that the daughter, Megan, could be in the classroom of a specific 
teacher whom they viewed favorably. Although there were disagreements regarding the approach to Megan's academic progress, Mrs. Adams describe the reason for removal from public education as "the teacher and I butted heads." Even though the same academic problems still existed when Megan returned to public school, there was a good relationship with the teacher, therefore the parent, student and teacher worked together to solve the other difficulties.

In the case of the Bailey Family, the daughter, Rebecca, initiated the return to public education, by telling her parents that she wanted to be with her friends. The parents were hesitant at first, because the reason Rebecca had asked to be home schooled was because of social interactions. The parents did feel as if Rebecca had matured significantly in the year and a half that she had been home school; thus, they agreed to let Rebecca return to public school.

The parents in the Carter Family decided that it was time for their two boys, Ryan and David, to return to school "to be around kids their own age." Even though Mrs. Carter believed that she could better meet the children's academic needs at home, in a one-to-one situation, she felt strongly that the boys needed friends. Again, ironically, both of the boys had attended public school in the past and were removed by the parents because they "had a lot of problems interacting with other kids..."

When the parents approached their sons regarding their return to public school, they readily agreed that they want to go back to school, especially to be around friends. It should be noted that neither of the boys knew any of the other students in the classroom that they attended upon their return. 
Social relationships were the most important factor in the families' decision to return the student of public school. Further, social relationships also play a key role in the decision to home school. Given the forgoing, it would be reasonable to conclude that for a successful transition to take place, students must establish positive relationships with their peers and teachers.

Although when this research question was established, it was not written to investigate the transition issue, nevertheless the information gleaned has tremendous impact on the successful transition of the home schooled student. This conclusion was supported by occurrences throughout the school year for all the students.

Rebecca Bailey struggled to establish positive social interactions with her peer group. Rebecca articulated the experience very well, "I got worried around November that I had made a bad mistake coming back to public school for the social reason. I mean, I had friends but nobody was really close at the time and I just started getting involved with more school activities and now I've got really, really good friends." If the student had not persisted in her attempts to make peer connections, the transition may not have been successful.

Moreover, the conclusion that social relationships are a key to successful transitions can be established through the experiences of the Carter Family. Ryan and David Carter, who had been home schooled on and off for four years, continued to have problems with social relationships. David only stayed in public school for two weeks and Ryan lasted approximately 160 of the 180 days in the school year.

Mrs. Carter explained that she removed David from school because of "personality conflict" with the teacher. However, records show and the teacher stated that David 
had difficulty outside the classroom setting getting along with other students. In the second semester of the school year, Mrs. Carter stated that Ryan had been suspended four times, "because he always had problems interacting with other kids, being comfortable around other kids because he is so shy." By May of that year, Mrs. Carter called the board of education to report that she was removing Ryan from school because "boys were picking on him." She also stated that the incidents were happening outside of the school environment and then continuing in school.

Ryan and David Carter's lack of establishing positive social interaction is the key factor in their unsuccessful transition to public school and ultimately caused their removal. Again, positive social interaction by the returning home schooler is an important indicator for successful transitions to public schools.

Given the foregoing, public schools need to be aware that returning home schooling students need to establish positive social relationships. Public schools would be prudent to initiate ways to encourage positive social relationships for these students. One student suggested a club that could meet under the supervision of a teacher. The club would be made up of all students who were "new" to the school. The student believed that the club would be an ideal situation for kids to talk about the difficulties of being in a new situation and also a vehicle to make friends with other newcomers.

An elementary school teacher talked about ways that she could subtly help new students to "fit in." The third grade teacher considered it part of her "job" to make sure students established positive peer interactions. The middle school teachers did not seem to feel this same responsibility as part of their "job description." 
Conclusion: A key factor in the home schooling family's decision to enroll or re-enroll their child(ren) in public schools was to establish positive social interactions with peers and teachers. Given the foregoing, schools need to consider ways that they could assist in facilitating positive social interactions for returning home schooling students.

Research Question \#2: What do home schooling guardians or families, who choose to enter or re-enter their children in public schools, believe public schools currently do and/or should do to support their children in their transition from home to school?

The home schooling families perception of what public schools are doing to support the returning home schooled student varied from a positive to a negative observation with each student. The belief that the student was being positively or negatively supported did not emanate from the school system in general, but rather from contact with the individual classroom teachers.

In the situation with the Adams Family, the mother, daughter, and teacher met before Megan returned to school. Although the family viewed the teacher in a very positive light pervious to the conference, the meeting helped to solidify this belief; therefore, the family believed that the student was being supported, as well as, emotionally.

Both of the Adams children, Megan and Evan also felt that the teachers were supportive to them. Megan stated that the teacher gave her extra help in the classroom. Evan believe that the teachers reviewed things with him as a way of paying more attention to and supporting him. This was the most positive of the returning students feeling supported. 
Mrs. Bailey noted that she believed home schooled students, in general, needed reinforcement and support more than other students because they were use to it. Being in a one-to-one learning situation gave the students constant feedback and reassurance. Mrs. Bailey thought that her daughter, Rebecca had developed friendships with most all of her teachers and viewed the support generally in a positive way.

In contrast, even though Rebecca Bailey said that she liked most of her teachers, she asserted that she could have used more support in the transition to public schools. The support she needed was in the initial return period and was in the nature of general reassurances. Rebecca also verbalized that her teachers did not question her about her academic studies throughout the home schooling experience and she felt that this information may have been valuable in the transition process.

Mrs. Carter felt that the youngest of her sons, David, was not supported by the teacher. Mrs. Carter stated, "I felt that she [the teacher] was biased because my son had been home schooled. She verbally made fun of some of his subjects and his abilities." As previously stated, the parent removed the student from public school due to this feeling of lack of support and "personality conflict" with the teacher, in addition to problems with peers. Additionally, David Carter's teacher noted, "David had a little difficulty with moving into the school environment," however, did not articulate any interventions that she attempted to remedy the situation.

Teachers also viewed home schooling students as needing more support in the classroom. All of the teachers interviewed felt that initially home schooled students were hesitant to participate in the classroom activities, i.e., answering questions, 
group activities and volunteering to lead others. The teachers also noted that the students were hesitant to ask for help if they did not understand something. The teachers related that they tried to help students academically and encouraged them to request assistance whenever they needed it. In most of the situations, this hesitancy dissipated with time and encouragement from the teachers.

The support and encouragement from teachers played an important role in the successful transition to public school. The public school teachers and parents seemed to recognize this phenomena; however, teachers seemed much more likely to provide support in the academic realm than in the emotional one.

It must also be noted that when the students seemed to need the most support was during the first few weeks and months of their return. Because in most of the cases the teachers were not notified that they had a returning home schooled student in their classrooms, it would be extremely difficult for the teacher to offer planned and intentional support. Particularly in a middle school setting, when a student would have multiple teachers throughout the school day, the teacher was at a disadvantage to glean the information regarding the history of home schooling if they are not notified from the school office. Therefore, if a teacher does not know the student's background, they cannot offer the needed support.

When educators and home schooling parents were asked what could the public schools do to support the returning home schooled student to school, both parties felt that there should be open lines of communication during the time the home schooling was taking place. It was suggested by both groups that a liaison at the board of 
education would be valuable in assisting home schooling families and make the transition back to public schools smoother.

All of the parents talked about the insecurities they experienced when they first began to home school, especially in the area of curriculum. The parents wanted more guidance in the area of academics and scheduling of lessons. Parents suggested that a liaison would assist home schooling parents to keep the students in line with their public school counterpart. One parent asserted that having a liaison "available, in a comfortable setting on occasion, would be appreciated and could enhance cooperation and understanding" between the school system and home schoolers. Parents also believed that if students covered the same curriculum, then the transition would be easier.

Educators also recognized the benefits of communicating with home school families while the student is out of the public school. Several of the teachers noted that both the parents and the school system were working towards the same goal, "to prepare them [the student] for the future." A middle school teacher explained, "If parents would know more about the public schools, what we taught- - the school curriculum, what is offered, I feel like that would make a big difference in helping their child adjust when returning to the public school system." Teachers felt that if home schooling parents were supported throughout their experience that students would be more apt to be on target academically, making the transition easier for the student.

To assist in making the transition into public schools smoother for parents, students and educators, many of those interviewed believed that communication 
throughout the home school experience was an important factor. Parents and educators identified the need for communication, particularly regarding curriculum, as a key element in a successful transition.

Conclusion: Support received by the returning home schooled students from public schools, i.e., classroom teachers, is haphazard, and varies from classroom teacher to classroom teacher. The classroom teacher is more apt to support a student academically than emotionally. Open lines of communication between public schools and home schooling families, especially in the area of curriculum, need to be established. Schools need to recognize and furnish planned, intentional support, both emotionally and academically, to returning home schooled students to facilitate a smooth transition.

Research Question \#3: What is the experience that home schooling students have upon entering or re-entering public schools and what could the public schools do to participate in that experience? What is the role of the public school in that experience?

Before entering public school, home schooling parents and students were apprehensive regarding the experience. Parents did not feel that the public schools viewed them as "teachers" and excluded them in the experience. The public school system seemed to be oblivious to the apprehension of the home schooling family and the omission of exchange of information from "teacher to teacher." Additionally, public schools, in general, have a negative connotation associated with home schooling. 
Parents and students participating in the study expressed anxiety about adjusting to public schools' curriculum; safety of the students; adjusting to school schedules and the student being able to measure up academically. The most prevalent concern was that of social interactions with other students and teachers. Perhaps returning home schooled student, David Carter, expressed this feeling best when he stated, "It was scary, kind of. Because I had never even saw the kids there before or the teachers." In contrast, three of the returning home schooled students did know some of their classmates when they returned to school, nevertheless, they were also apprehensive about the experience.

All the aforementioned areas of apprehension could be addressed by a "teacher to teacher" exchange of information, although for the exchange to occur, public school teachers must view the "parent as a teacher." The home schooling parents did not feel that public school teachers regarded them from this frame of reference. However, the majority of the public school teachers said that they could conference with the home schooling parent from this perspective- "teacher to teacher."

Nevertheless, none of the public school teachers interviewed ever approached a home schooling parent to glean information regarding learning styles of students, academic abilities, curriculum that was utilized or the social abilities of the students. Furthermore, parents did not attempt to share this information with the teachers either. One conference did occur between the home schooling parent and teacher, however the topics of learning styles, curriculum utilized or social abilities were not discussed. 
Admittedly, a conference between parents and teachers has been determined to be an important component of a successful transition, the "teacher to teacher" relationship goes beyond the conference. A mutual respect between the parent and teacher must be established and an exchange of information supported.

For the public schools to take an active role in the experience of returning home schoolers, there must be a relationship between the parents and public school teachers. Schools must also recognize that there is a transition taking place. The public school system, i.e., central office or local school administration, did not take an active role in the transition process throughout the study. The individual relationship with the classroom teacher seemed to be the only relationship with the public school for the home schooling family.

Because the teacher's role in the transition represents the public school, the teacher's attitude toward home schooling was an important issue and a determining factor in the experience of transition. The large majority of the teachers interviewed did not generally view home schooling in a favorable way. The public school educators questioned if home schooled students were receiving the best possible educations in the following areas: socialization with other students; higher level academics and exposure to different races, economic backgrounds and religions.

As previously stated, ironically, the same teachers who had negative general beliefs regarding home schooling, did not have that same feeling when they discussed individual home schoolers. Teachers expressed much more favorable observations when discussing individual home schoolers. In all but two cases, the teachers had not observed any of the things that they had characterized as potential problems. The 
majority of the teachers stated that the returning home schooled students were well adjusted, had made friends and seemed to be on level or above level academically. It should also be noted that the overwhelming research in this area found that home schooled students did not suffer academically or socially from their experience.

Conclusion: Public schools, i.e., central offices and local school administrations, need to consider taking an active role in the transition of returning home schooled students. Public school teachers need to examine their beliefs regarding home schooling and revise those beliefs based upon research and their own personal experiences. Further, the role of the public school in the transition could be enhanced by conferencing with the "parent as a teacher" of the home schooling student.

Research Question \#4: What are the critical issues embedded in the transition from home schooling to public schools for guardians/parents, children and educators?

The most critical issues embedded in the transition of home schooling students to public schools were conferences among the parents, students and educators before the student returns to public school and the social relationships formed by the returning home schooling student with peers and teachers. The success of the transition for the returning home schooling student seemed to be directly related to these issues.

All public school educators and parents and some of the students agreed that a conference before the child returned to public school would be beneficial to a successful transition. The public school teachers suggested that the conference would be useful in learning more about the academic background of the student, that is, curriculum used and the amount of material that was covered. One of the teachers 
also asserted that the conference was a valuable tool because it was a time when they could assure the parent that they both had the best interests of the child in common.

The parents viewed the conference as an opportunity to discuss their concerns about the transition. Mrs. Bailey, the parent of the eighth grader stated, "I would beg them [teachers] to have a little bit of patience that first month and please, please, please tell me if there is anything I can do to make it easier." Parents also wanted to share their child's learning style and their strengths and weaknesses.

Students also thought that a conference would be advantageous to them. Megan Adams, the only student whom did attend a conference, said that she was able to tell her teacher that she was worried about "comprehension." Megan felt better when the teacher assured her that she would get help in this area.

More than one parent and educator suggested that it should be mandatory that the home schooling parent and the public school teacher meet before the child enters school. However, whether they felt that it should be mandatory or voluntary, all the home schooling parents and public school teachers believed that it would be beneficial for a conference to occur.

It is my belief that the most important aspect of the conference among public school educators, home schooling parents and the returning student would be face-toface contact. By directly interfacing with each other a relationship would be established. If parents and public school teachers established the belief that the child's success was a shared mutual concern, everyone involved would benefit. In other words, regardless of what is discussed in the conference, as long as it is a 
positive experience, the concerns and apprehensions of the parent and student, and in some cased the teacher, would be quelled.

Of all the issues, that of social relationships seemed to have the greatest direct effect on the success of the transition. All three of the families participating in the study removed their children from public schools, in part, due to negative social relationships. Furthermore, all three of the families returned their children to the public school in the hopes of establishing positive social relationships.

Mrs. Carter, parent of David and Ryan, explained the importance of social relationships and stated, “When they [the students] don't fit in, they don't care about their grades or anything else. They start talking to more kids and becoming friends, things get better for them and they feel good about thierself (sic)."

Each of the returning home schooled students had very different experiences in the area of social relationships and the success of their transition also varied. Evan Adams had never had a problem in this area, continued to "fit in" well with his peers. Megan Adams established a close, respectful relationship with her teacher and felt successful in the public school transition. Rebecca Bailey initially struggled with establishing positive relationships with her peers. At one point, she questioned her decision to return to public school because of her difficulties in this area. However, by the end of the first semester, Rebecca had developed "a nice little circle of close friends" and stated, "This has been the best year that I've had at school."

David and Ryan Carter had a difficult time making friends and with social interactions in general. Ryan Carter only attended public school for two weeks, following a pattern from his past. David Carter attended school for most of the year, 
however, he returned to home schooling when he was "picked on" by other students. The lack of or negative social relationships of the Carter children and their unsuccessful attempt to reenter public education, seem to support the direct relationship direct between a successful transition and the formation of positive social relationships.

Rebecca Bailey suggested that a club be formed in schools for retuning home schooled students. The club's main function would be to discuss problems and concerns and, also, to facilitate friendships among the new students.

Teachers also recognized the importance of students developing positive social relationships. One elementary educator explained that she was subtle when she facilitated new friendships for her new students, considering it part of her job to assist students in "fitting in."

Conclusion: Conferences should be held among public school educators, home schooling parents and students before the child enters public school. Public schools should facilitate and encourage a conference. The development of positive social relationships by the returning student play a key role in the successful transition of home schooling students back to public school. Therefore, public schools should investigate formal and informal practices that encourage positive social interaction for returning home schooled students.

Dual enrollment in public school and home school

The concept dual enrollment in home school and in public school has been receiving more respect and consideration. Education reform leader Theodore Sizer, stated, "It's either 'You come to my school all the time' or 'I'll keep my kid at home 
and teach her.' Let's not get caught up in that either-or catfight” (Sharp 1997, 5). Sizer contended that children would be best served if every home was a "quasischool" where parents supplement what children learn elsewhere. "We shouldn't think schools do everything about intellectual training any more than homes do," Sizer observed (Sharp 1997, 6).

Although the school district in which the study took place was empowered by state law to allow students to attend school part time, the local board of education has opted not to allow this arrangement. Students who were identified as having special needs, such as speech problems or required supplemental gifted education, were served by the public school system, part time, as regulated by state and federal laws. In contrast, to this local decision, Sharp stated, "Home schooling families pay an annual average of $\$ 500$ per child for supplies. As taxpayers, many think their kids should be able to take public school classes, too" $(1997,5)$.

All of the returning home schooled students embraced the idea of attending public school part time and being home schooled the rest of the day. One of the middle school students who participated in the study suggested that everyone should consider taking their core classes at home and electives, computer classes and lab classes at public school. Rebecca Bailey stated, "I think that would be good for everybody, not just having public schooling where you take everything."

Parents also agreed that dual enrollment was a concept that deserved consideration. Mrs. Bailey felt that dual enrollment would offer students the best of both worlds and stated, "The concept [dual enrollment] is a good one, and should be offered routinely to home schooled students. Obviously, the variety of labs, adult role 
models, social and intellectual interaction of public school cannot be approximated at home."

The parent of David and Ryan, Mrs. Carter, also thought that part time attendance would be beneficial. Mrs. Carter stated, "They [the student] would still have an outside life...they'd still have friends. The things the parents are lacking in the studies, maybe the school could make up on that end. The parents can give them oneto-one at home."

Teachers addressed part time attendance on a much more temporary basis—as a way to ease students back into public school. One teacher suggested that the student should "...go to school and visit for a few hours, go to a classroom and see how things operate so the child would have a general idea of what to expect when they come back to school after having been home schooled." The idea of easing back into public school was one that parents and students also supported, however, permanent dual enrollment seemed to interest them much more.

Some educators agreed that their mission was to educate all children, including home schooled children. Recently, a Maine principal assisted the local home schooling association develop a policy which allows home schoolers access to resources and facilities, as long as their presence does not disrupt the regular school day. The policy has provisions for home schooled students to attend regular classes; qualify for special education services; participate in co-and extracurricular activities; use facilities, equipment, and school texts and library books and earn course credit and a high school diploma (Rasmussen 1999). 
The principal observed that some of the full time students' parents objected to a home schooler playing on a sports team. Sykes explained, "We try to prevent this by having the same academic and behavior requirements for all students...but parents of home schooled students are taxpayers and residents of our community, so their kid has the right to be there" (Rasmussen 1999, 4).

The concept of dual enrollment was still a very new one when this study occurred. Parents, students and teachers who participated in the study considered the idea of part time attendance in public schools favorably, although, many of the interviewees had not explored this possibility before the concept emerged from the study. Conclusion: Dual enrollment in public school and home school is becoming a more prevalent concept. Parents and students who participated in the study embraced the idea of permanent dual enrollment in public school and home school. Public school educators viewed part time attendance as a temporary arrangement to assist in easing home schooled students back into public school. State and local boards of education need to review policy regarding dual enrollment in public and home schools. The boards of education need to consider the benefits for students of dual enrollment and adjust policies accordingly. $\underline{\text { Implications }}$

A generation ago, home schoolers were pioneers and oddities. Now, "almost everyone" knows a family which chooses to home school their children. "Home schooling is the choice of 100 times more American families than 20 years ago. Today it's mainstream, middle-class..." (Sharp 1997, 4). Therefore, the implications 
of this study should be taken seriously by parents, communities, boards of educations and policy makers, at all levels.

As a result of reviewing and analyzing the responses to the survey and interview questions, and as a result of reaching the conclusions listed prior to this section, suggestions are offered for both opponents and advocates of home schooling. These recommendations are offered primarily for consideration by the West Virginia local boards of education and individual West Virginia public schools.

Because West Virginia state code provides for most decisions regarding home schooling to take place at the local level, the following recommendations are suggested for consideration by West Virginia local boards of education:

- Revise policies to provide for maximum flexibility to the district in meeting the needs of all students, in this case, home schooling students.

- Provide technical assistance and open lines of communication to home schooling families, especially in the area of curriculum, via a liaison at the central office level.

- Initiate and implement a program which provides for a planned, active role in the process of transition of returning home schooled students.

- Provide for dual enrollment in public and home schools so that students can receive the best possible education.

The following recommendations are suggested for consideration by West Virginia local schools:

- Assume an active role in the transition of returning home schooled students. 
- Develop and implement formal and informal practices which provide for positive social interactions for returning home schooling students.

- Develop and implement a policy which stipulates that returning home schooled students, their parents, school administrator and the classroom teacher must conference before the home schooled student returns to school. The public school should glean information from the "parent as a teacher" regarding the child's academic abilities, interests, learning styles and apprehensions. Information should also be provided by the school regarding policies, expectations, communication, rules and regulations.

- Recognize and furnish planned, intentional support, both emotionally and academically, to returning home schooled students.

Rasmussen (1999) explained that home schoolers and public school staffs need to remain "open-minded" if a partnership is to be nurtured and established. "We need to work together-parents, the community, the public schools, the government. We're all in this together" (4).

\section{$\underline{\text { Recommendations for Future Research }}$}

While this qualitative study has examined the critical issues embedded in the transition of returning home schooled students to public schools, the issue can also be studied from many other perspectives. First, additional research could be conducted from a quantitative approach investigating the transition process for returning home schooled students to public schools. Evidence discovered in this study could be utilized to formulate surveys for all the populations involved in the transitionparents, students and educators. 
Because the phenomena of social interactions was found to be a deciding factor in the decision for families to decide to home school and in the decision to return home schooled students to public school, additional studies need to be conducted in this area. The majority of past research indicated that the most prevalent reason families choose to home school were based on religious issues. A qualitative study investigating the reasons families choose to home school could more decisively define these choices.

Further, in regard to the issue of social interactions of home schooled students, longitudinal studies could provide valuable information regarding the ability of the children who are home schooled to adapt to the broader social world. The study could investigate the home schooled students' social ability to acclimate multiple social situations, including structured peer group interaction, informal peer group interactions and adult interactions.

Finally, the teaching methods that the parent employees throughout the home school experience should be researched more thoroughly. When making the transition from home to school, students must abandon the learning style of one-to-one teaching and adjust to group instruction. This study found that students were apprehensive to participate in groups; therefore, investigating the daily routines in home schools would be valuable for understanding difficulties in adjusting from small to large groups in the transition process. 


\section{References}

Breshears, Shirley Mae. 1996. Characteristics of home schools and home school families in Idaho. Ph.D. diss., University of Idaho.

Bunday, Karl M. 1995. "Homeschooling is Growing Worldwide." School is Dead, Learn in Freedom Website, Excelsior, MN: 1-8.

Chatham-Carpenter, April D. 1992. Home vs. Public Schooler's Relationships: Differences in Social Networks. Doctoral diss. University of Iowa.

Coleman, James S. 1987. "Families and Schools." Educational Researcher 16 (August-September): 32-38.

Colfax, David and Micki. 1988. HomeSchooling For Excellence. New York, NY: Warner Books, Mountain House Press.

Clark, Charles S. 2000. "Home and Away.” Teacher Magazine (October): 9-10.

Daggett, Willard. 1994. “Today's Students, Yesterday’s Schooling.” Executive Educator 16 (June):16-17.

Dahm, Leslie. 1996. "Education at Home, With Help from School” Educational Leadership 54 (October): 68-71.

Divoky, Diane. 1983. "The new pioneers of the home-schooling movement." Phi Delta Kappan 64 (February): 395-398.

Easterbrooks, Jim. 1988. "Helping Home Schoolers with a Quality Curriculum." Thrust 17 (April): 10-11.

Fash, Charles Louis. 1994. Issues relating to the education of children in the home setting. Ed. D. diss., Northern Arizona University.

Golding, Patricia Surratt. 1995. A study of ways home schooling families in southwest Virginia believe public schools can better interface and assist families who choose to home school their children. Ph. D. diss., Virginia Polytechnic Institute and State University.

Gray, Steven. 1992. Why some parents choose to home school (school choice). Ph. D. diss., University of California, Los Angeles.

Guterson, David. 1998. “No Longer a Fringe Movement.” Newsweek. 182 (October 5): 71. 
Harbottle, Stephen Daniel. 1995. A pragmatic legal critique of parents' constitutional right to home educate their children (home schooling). Ph. D. diss., University of Michigan.

Hern, Matt, Ed. 1996. Deschooling Our Lives. Philadelphia, PA: New Society Press.

Hill, David. 1993. “Teach Your Children.” Teacher Magazine. (February):16-23.

Hines, Paul Matthew. 1993. Home schooling in Arkansas: A study of attitudes, family characteristics, and student achievement. Ed. D. diss., University of Arkansas.

Holt, John. 1983. "Schools and Home Schoolers: A Fruitful Partnership." Phi Delta Kappan. 64 (February): 391-394.

Holtrop, Stephen D. 1996. "Individualization Starts At Home.” Educational Leadership. 54 (October): 74-76.

Kantrowitz, Barbara and Pat Wingert. 1998. "Learning At Home: Does It Pass the Test?" Newsweek. 132 (October 5): 64-70.

Klicka, Christopher J. and Douglas W. Phillips. 1997. "Why Parental Rights Laws Are Necessary.” Educational Leadership. 55 (November): 76-83.

1989. Home Schooling in the United States: A Statutory

Analysis. Home School Legal Defense Association.

Kleiner, Carolyn. 2000. "Home School Comes of Age." U.S. News and World Report. 129. (October): 52-54.

Kozol, Jonathan. 1991. Savage Inequalities: Children in America's Schools. New York, NY: Crown Publishers.

Lines, Patricia M. 1987. “An Overview of Home Education.” Phi Delta Kappan. 68 (March): 510-517.

1996. "Home Schooling Comes of Age." Educational Leadership. 54 (October): 63-67.

Maness, Donald Chester. 1988. To home school or not to home school: Selected characteristics of home school families in Bartlesville, Oklahoma, area and the Sioux Falls, South Dakota, area. Ed. D. diss., Oklahoma State University. 
Marklein, Mary Beth. 2000. "Home-schoolers Declare Their College Independence." USA Today. 232 (February): 8D.

Mayberry, Maralee, J. G. Knowles, Brian Ray and S. Marlow. 1995. Home Schooling: Parents as Educators. Thousand Oaks, CA: Corwin Press.

McRae, Hamish. 1995. The World in 2020. Boston, MA: Harvard Business School Press.

Miller, Eric. 1991. "Home Schooling--Does It Pass the Test?" Rural Living. (September): 19-25.

Natale, Jo Anna. 1992. "Understanding Home Schooling." The American School Board Journal. 170 (September): 26-29.

Ordovensky, Pat. 1996. Test Critics Decry Trend. USA TODAY, 25-27 October.

Parsons, Kent Richard. 1995. Home schoolers: Their academic and social wellbeing and their use of public libraries in Willow, California. Ed. D. diss., University of California, Berkeley.

Perelman, Lewis J. 1992. School's Out. New York, NY: Avon Books.

Pitman, Mary Anne. 1997. "Compulsory Education and Home Schooling: Truancy or Prophecy?" Education and Urban Society. 19 (May): 280-289.

Prince, Karen Marie. 1995. A qualitative description of the beliefs and practices of home schooling families as they relate to the development of emergent literacy among young children within the home school. Ed. D. diss., Temple University.

Ramsay, Krista. 1992. "Home Is Where the School Is." School Administrator. 49 (January): 20-25.

Rasmussen, Karen. 1999. "Partners in Education: How Schools and Homeschoolers Work Together." ASCD Education Update. 41 (June 1999): 1-5.

Ray, Brian D. 1992. "Marching to the Beat of Their Own Drum: A Profile of Home Education Research." Home School Legal Defense Association. Paeonian Springs, VA. . 1990. "A Nationwide Study of Home Education: Family Characteristics, Legal Matters, and Student Achievement." Study conducted by The National Home Education Research Institute. Reported in the Home School Court Report. Home Legal Defense Association. 

. 1988. "Home Schools: A Synthesis of Research on Characteristics and Learn Outcomes." Education and Urban Society. 21 (November): 16-31.

Roach, Virginia. 1988. "Home Schooling in an Era of Educational Reform." School Business Affairs. 54 (November): 10-14.

Sharp, David. 1997. "Your Kids' Education Is At Stake.” USA Weekend. (March): 4-6.

Strange, Stephen Kelly. 1994. Home school families: Description, characteristics and practices. Ed. D. diss., Indiana University.

Strout, Richard Maurice. 1993. Home schooling in the United States: A legal review and analysis (Oklahoma, Kansas, Missouri). Ed. D. diss., University of Tulsa.

Swartzlander, Emily. 2000. "One Family's Experience With Homeschooling." Bluefield Daily Telegraph. 106 (August) 7.

Taylor, Lesley Ann. 1997. "Home In School: Insights on Education Through the Lens Of Home Schoolers.” Theory Into Practice. 36 (Spring): 110-116.

Thornburg, David. 1992. Edutrends 2010. San Carlos, CA: Starsong Publications.

Van Galen, Jane Ann. 1986. Schooling in private: A study of home education. Ph. D. diss., University of North Carolina at Chapel Hill.

Whitehead, John W. and Alexis Irene Crow. 1993. Home Education-Rights and Reasons. Wheaton, IL: Crosway Books, Good New Publishers.

Winters, Rebecca. 2000. "From Home to Harvard.” Time. (September): 55 


\title{
Appendix A
}

\author{
Survey Letter
}

\section{Dear Parents,}

I am a doctoral candidate in Advanced Leadership Studies at West Virginia University. As part of the requirements for this degree, and I am conducting a study on the transition of home schooled children to public schools. The attached survey is the basis for the study.

I would be most appreciative if you would take the time to complete the survey, seal it in the envelop provided and mail it to me. Your participation in this study is voluntary, but the information provided will be valuable to the study. When completing this survey, please bear in mind that you have the right not to respond to every item.

Please rest assured that your responses will remain confidential. No individually identified responses will appear in the course of this research.

Total confidentiality and anonymity will be maintained.

Thank you very much in advance for taking the time to answer the questions in the survey.

Sincerely yours,

Anne M. Krout 


\section{Appendix B}

\section{Home Schooling Parent Survey}

1) Are you presently home schooling your child(ren)?

2) How many years have you or did you home school your child(ren)?

Child \#1 years, from grade to

Child \#2 years, from grade to

Child \#3 years, from grade to

3) Please complete each of the following questions for each child in your home:

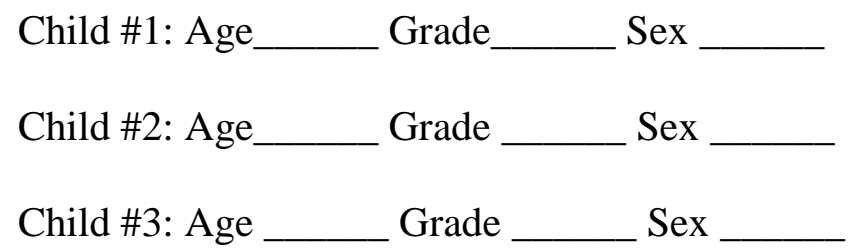

4) What is the highest level of education you have completed? (Please circle)

Mother: (1) less than 12 years (2) high school degree (3) GED (4) some college, no degree (5)Associate Degree, occupational/vocational (6) Bachelor's Degree (example, BA, AB, BS) (7) Master's Degree (8) Doctoral Degree (example, MD, DDS, DVM, Ph.D., Ed.D)

Father: (1) less than 12 years (2) high school degree (3) GED (4) some college, no degree (5)Associate Degree, occupational/vocational (6) Bachelor's Degree (example, BA, AB, BS) (7) Master's Degree (8) Doctoral Degree (example, MD, DDS, DVM, Ph.D., Ed.D)

5) Were you home schooled?

6) Was anyone else in your family, besides your child(ren) home schooled?

7) What are the occupations of:

the child's Mother the child's Father 
8) Do you have a computer at home? Do you or did you use it for instruction?

9) Do you or did you belong to a home school association?

10) Describe the reason(s) you first home schooled your child(ren).

11) Are there any pre-school children in your home? Do you plan to home school them?

12) If you are presently home schooling your child(ren), do you plan to enter or reenter your child(ren) in public school in the future?

(If yes, please indicate at which grade level by circling)

Grade $1,2,3,4,5,6,7,8,9,10,11,12$ Undecided

13) If you have chosen to return or plan to return your child(ren) to public school, describe the reason(s) for that decision. 


\section{Appendix C}

\section{Checklist for Validation}

(To be answered by the pilot study family)

1. Are the questions to the parents clear and concise?

a. yes

b. no

If no, please indicate the item number and comment.

2. Are the questions clearly stated so that only one interpretation is possible?

a. yes

b. no

If no, please indicate the item number and comment.

3. Are all the terms and words clearly understood by the parents?

a. yes

b. no

If no, please indicate the item number and comment.

4. Are there any recommendations you have to improve this questionnaire:

a. yes

b. no 


\section{Appendix D}

The following chart indicates the highest level of education completed by the home schooling parent.

\begin{tabular}{|l|c|c|c|c|c|c|c|c|c|}
\hline & $\begin{array}{c}\text { Less } \\
\text { than } \\
12 \\
\text { years }\end{array}$ & $\begin{array}{c}\text { High } \\
\text { School } \\
\text { Degree }\end{array}$ & GED & $\begin{array}{c}\text { Some } \\
\text { college, } \\
\text { no } \\
\text { degree }\end{array}$ & $\begin{array}{c}\text { Associate } \\
\text { Degree }\end{array}$ & $\begin{array}{c}\text { Bach- } \\
\text { elor's } \\
\text { Degree }\end{array}$ & $\begin{array}{c}\text { Master's } \\
\text { Degree }\end{array}$ & $\begin{array}{l}\text { Doctoral } \\
\text { Degree }\end{array}$ & $\begin{array}{l}\text { No } \\
\text { answer }\end{array}$ \\
\hline Mother & 0 & 1 & 1 & 3 & 4 & 5 & 2 & 0 & 1 \\
\hline Father & 1 & 0 & 1 & 3 & 2 & 1 & 5 & 1 & $3 *$ \\
\hline
\end{tabular}

*One of the no answers indicated that there was no father in the home. 


\section{Appendix E}

The following chart illustrates the occupations of the home schooling parents.

The number indicates the family responding. Some of the responders indicated more than one occupation.

\begin{tabular}{|c|c|c|}
\hline Occupation & Mother & Father \\
\hline Nurse & 1,7 & 7 \\
\hline Management & & 1 \\
\hline Teacher & 2,16 & \\
\hline Physician & & 2 \\
\hline Artist & 3 & \\
\hline Commodities Trader & & 3 \\
\hline Housewife & 4,15 & \\
\hline Homemaker & $5,6,8,11,13,17$ & \\
\hline Plant manager & & 4 \\
\hline Professional Medical Field & & 5 \\
\hline Pharmacist & & 6 \\
\hline Minister & & 8,9 \\
\hline Secretary & 9 & \\
\hline Coach & & 9 \\
\hline Disabled & 10 & 10 \\
\hline Correction Officer & & 11 \\
\hline
\end{tabular}




\begin{tabular}{|c|c|c|}
\hline Federal employee & & 13 \\
\hline Post Office employee & 14 & \\
\hline Business woman & 16 & 15 \\
\hline Lineman & & 16 \\
\hline Student & & 16 \\
\hline Sales engineer & & 17 (deceased) \\
\hline Volunteer & 16 & 12 \\
\hline Coal Miner & & 14 \\
\hline No Answer & 12 & \\
\hline Not Applicable & & \\
\hline
\end{tabular}




\section{Appendix F}

\section{Summary of full responses given as to why home school families first home}

\section{schooled their children.}

Family \#1:1) Control of philosophical influence during critical formative years of child's development, i.e., Biblical foundation of morals; 2) safety and 3) better control of discipline and immediate obedience.

Family \#2: 1) Obedience to Deut. 6-teaching children of the ways of the Lord, at all times; 2) develop a Christian world view for my children; 3) test scores show home schooled children perform better academically; 4) present day consideration is physical safety for one's children and 5) to avoid the negative socialization that occurs in the school setting.

Family \# 3: We use to live in Florida, where the level of violence in schools was increasing. We also disagree with the heavy reliance on psychiatric involvement in the education system.

Family \# 4: The public school that the oldest [child] attended gave him high grades in subjects he had no knowledge. We prayed and felt directed to home school.

Family \#5: Our nation has steadily declined in its morals. Thus, I feel it has affected our schools and our children. Anything goes, and nothing is wrong. We are to accept every type of life style and condemn none. Many of these thing are being taught to our children in public schools. The actual subject may not be taught, but none the less the concepts are conveyed.

As a child of God I want my children to be taught that there are rights and wrongs. God does expect holiness as the way that we should live. 
Sex education is a big issue in school that concerns me. Yes, our children must be informed of God's design for sex. But, I feel it should be done by the parents in a Godly setting. We teach our children safe sex instead of abstinence. It is not O.K. to accept the ways of the world.

I want God to be a part of everything in their lives, including school. I want them to be aware of His creativity and abilities in every subject we study.

Family \#6: Four of our children are adopted and were in two separate foster homes. Home schooling has allowed us to put this family group back together. [Two additional children attend a Christian School.] Home schooling allows us to have flexibility in scheduling. If issues of adoption, abuse and neglect arise during the day, we can deal with it immediately. My husband's work schedule varies from week to week, home schooling allows us more family time and he can also participate in their home schooling. Home schooling removes the stress of homework and/or remaining on a particularly difficult concept until it is mastered.

Family \#7: What appeared to us as the inability of the middle school staff to deal with unsafe situations and a general atmosphere of indifference to bullying, crude and disruptive children.

Family \#8: 1) Character development; 2) individual attention; 3) religious beliefs and 4) safety.

Family \#9: After moving into the area, we wanted to evaluate the Christian school choices before making a decision. We feel home schooling is the best, if done correctly. 
Family \#10: My children are special education and I can do better than the school and they won't be teased more than necessary and I want to raise good, wellbehaved children and other special education kids are mean.

Family \#11: Her third grade teacher was very rude and intentionally cruel, not only to her but the other students as well. After trying to talk with him and the principal and the school board, no action was taken to remedy the situation. I felt it was best if she was removed from that classroom.

Family \#12: I believe that God has given me the responsibility to teach and train my children and that I am ultimately responsible to Him for their upbringing. I feel it is a privilege to be with my children — they grow up so fast and [it is] a joy to watch them learn and grow. I feel I can give them more one-on-one time than in a typical classroom setting.

Family \#13: 1) Religious, 2) socialization, 3) benefits, 4) better education and 5) teaching of life skills.

Family \#14: We moved to this state and discovered the school system is totally uncaring, unresponsive and behind in academics to the point that our son was.

Family \#15: Because of a move, child was unable to cope, loss of weight, doctor suggested home schooling.

Family \#16: Too much to write; not enough space. Three students—different circumstances and different reasons.

Family \#17: It was at my daughter's request I started home schooling. She was having trouble learning at school, especially in math. 
The following chart summarizes the narrative responses of the families. It should be noted that family \#16 did not give specific reasons why they home schooled and stated, "Too much to write; not enough space. Three students—different circumstances-different reasons." 
Appendix G

The following chart indicates the reasons why families began to home school.

\begin{tabular}{|c|c|c|c|c|c|c|c|c|c|c|c|c|c|c|c|c|c|}
\hline \multicolumn{18}{|c|}{ Family } \\
\hline Reasons & 1 & 2 & 3 & 4 & 5 & 6 & 7 & 8 & 9 & 10 & 11 & 12 & 13 & 14 & 15 & $16^{*}$ & 17 \\
\hline Religious & $\mathrm{X}$ & $\mathrm{X}$ & & & $\mathrm{X}$ & & & $\mathrm{X}$ & $X$ & & & $\mathrm{X}$ & $\mathrm{X}$ & & & & \\
\hline Safety & $\mathrm{X}$ & $\mathrm{X}$ & $\mathrm{X}$ & & & & $\mathrm{X}$ & $\mathrm{X}$ & & & & & & & & & \\
\hline $\begin{array}{l}\text { Control of } \\
\text { behavior/ } \\
\text { Control of } \\
\text { discipline }\end{array}$ & $\mathrm{X}$ & & & & & & & & & $\mathrm{X}$ & & & & & & & \\
\hline $\begin{array}{l}\text { Better } \\
\text { Education }\end{array}$ & & $X$ & & $\mathrm{X}$ & & & & & & $\mathrm{X}$ & & & $\mathrm{X}$ & $\mathrm{X}$ & & & $\mathrm{X}$ \\
\hline Socialization & & $\mathrm{X}$ & & & & & & & & & & & $\mathrm{X}$ & & & & \\
\hline $\begin{array}{l}\text { Psychiatric } \\
\text { involvement } \\
\text { in public } \\
\text { education }\end{array}$ & & & $\mathrm{X}$ & & & & & & & & & & & & & & \\
\hline $\begin{array}{l}\text { Promote } \\
\text { family unity }\end{array}$ & & & & & & $\mathrm{X}$ & & & & & & & & & & & \\
\hline $\begin{array}{l}\text { Flexible } \\
\text { scheduling }\end{array}$ & & & & & & $\mathrm{X}$ & & & & & & & & & & & \\
\hline $\begin{array}{l}\text { Remove } \\
\text { stress of } \\
\text { homework }\end{array}$ & & & & & & $\mathrm{X}$ & & & & & & & & & & & \\
\hline $\begin{array}{l}\text { Bullying in } \\
\text { school }\end{array}$ & & & & & & & $X$ & & & $\mathrm{X}$ & & & & & & & \\
\hline $\begin{array}{l}\text { Character } \\
\text { development }\end{array}$ & & & & & & & & $\mathrm{X}$ & & & & & & & & & \\
\hline $\begin{array}{l}\text { Individual } \\
\text { attention }\end{array}$ & & & & & & & & $\mathrm{X}$ & & & & $\mathrm{X}$ & & & & & \\
\hline $\begin{array}{l}\text { Treatment } \\
\text { by teacher/ } \\
\text { uncaring } \\
\text { school } \\
\text { system }\end{array}$ & & & & & & & & & & & $\mathrm{X}$ & & & $X$ & & & \\
\hline $\begin{array}{l}\text { Teach life } \\
\text { skills }\end{array}$ & & & & & & & & & & & & & $\mathrm{X}$ & & & & \\
\hline $\begin{array}{l}\text { Student } \\
\text { unable to } \\
\text { cope }\end{array}$ & & & & & & & & & & & & & & & $\mathrm{X}$ & & \\
\hline
\end{tabular}


Appendix $\mathrm{H}$

\section{Following are the full response of home schooling parents as to why they plan to return their child(ren) to public school.}

Family \#1: Would consider public school if Bible were taught in all grades; general perception of discipline in schools is good, with the exception of two middle schools and one high school.

Family \#6: Burnout on the part of the parent(s) — through prayer, feel that it is in the best interest of the child to have them reenter the school system.

Family \#7: As an only child, she misses the interaction with peers. She had many friends in elementary school and would like to rejoin them. Also, we realize our limitations in presenting her with only one side, while a whole staff of educators has the advantage of many backgrounds and points of view.

Family \#9: My children were in a Christian school and we plan to return them to one.

Family \#11: In hopes her fourth grade teacher can and will handle the classroom with a better attitude toward all the children. I feel she needs to be around her peers and the everyday atmosphere of school without the negative attitude of some of the teachers.

Family \#14: The only reason is to attempt a diploma. Had this system not ignored the constant threats, harassment of my son, he would have finished or remained in school. My daughter was LD—came here with all records in tact—-this system conveniently lost all records, gave her no help. They both failed by mere points. If it had been Virginia schools, I would have been notified and then the 
situation could have been rectified before it was too late. Perhaps, instead of working two positions to support us, I should have signed up on welfare and then maybe the school system would have been more cooperative.

Family \#17: It is my daughter's desire to return to school. Also, I do not have four years ahead of her in public schooling, I understand this a requirement. 
Appendix I

The following chart summarizes the narrative responses of the families as to why they plan to return their child(ren) to public school.

Family

\begin{tabular}{|l|l|l|l|l|l|l|}
\hline $\begin{array}{l}\text { Reasons for } \\
\text { returning to } \\
\text { public } \\
\text { education }\end{array}$ & 1 & 6 & 7 & 11 & 14 & \\
\hline $\begin{array}{l}\text { If Bible were } \\
\text { taught }\end{array}$ & $\mathrm{X}$ & & & & & \\
\hline $\begin{array}{l}\text { Burnout of } \\
\text { parents }\end{array}$ & & $\mathrm{X}$ & & & & \\
\hline $\begin{array}{l}\text { Interaction } \\
\text { with peers }\end{array}$ & & & $\mathrm{X}$ & $\mathrm{X}$ & & \\
\hline $\begin{array}{l}\text { Exposure to } \\
\text { other ideas }\end{array}$ & & & $\mathrm{X}$ & & & \\
\hline $\begin{array}{l}\text { Enroll in a } \\
\text { specific } \\
\text { classroom }\end{array}$ & & & & $\mathrm{X}$ & & \\
\hline $\begin{array}{l}\text { Attain } \\
\text { diploma }\end{array}$ & & & & & $\mathrm{X}$ & \\
\hline $\begin{array}{l}\text { Parent } \\
\text { cannot meet } \\
\text { state } \\
\text { requirements }\end{array}$ & & & & & & \\
\hline
\end{tabular}


Appendix $\mathbf{J}$

Parent or Guardian Consent and Information Form

Home Schoolers' Transition to Public Schools in West Virginia

I, have been invited to participate in this research study

which has been explained to me by Anne M. Krout. This research is being conducted to fulfill the requirements for a doctoral dissertation in Advanced Leadership Studies at West Virginia University.

The purpose of this study is to learn move about home schoolers transition to public schools in West Virginia.

This study involves a series of interviews and will take approximately two hours for me to complete. Approximately 16 subjects will be entered in this study. The interviews will be audio taped.

There are no known or expected risks from participating in this study.

I understand that this study is not expected to be of direct benefit to me, but the knowledge gained may be of benefit to others.

For more information about this research, I can contact Dr. Phyllis Durden, Anne Krout's advisor, at West Virginia University by calling (304) 293-3707 at extension 1424. For information regarding my rights as a research subject, I may contact the Executive Secretary of the Institutional Review Board at (304) 293-7073.

I understand that any information about me obtained as a result of my participation in this research will be kept as confidential as legally possible. I understand also that my research records, just like hospital records, may be subpoenaed by a court order or may be inspected by federal regulatory authorities. In any publications that result 
from this research neither my name nor any information from which I might be identified will be published without my consent. The audiotapes used in recording the interviews will be kept in a locked storage area throughout the study. When the study has been completed, the audiotapes will be destroyed.

Participation in this study is voluntary. I understand that I am free to withdraw my consent to participate in this study at any time. Refusal to participate or withdrawal will involve no penalty or loss of benefits. I have been given the opportunity to ask questions about the research, and I have received answers concerning areas I did not understand.

Upon signing this form, I will receive a copy.

I willingly consent to participate in this research.

Signature of Subject or Subject's Representative

Date

Time

Signature of Investigator

Date

Time 


\section{Appendix K}

Parent or Guardian Consent and Information Form

\section{Home Schoolers' Transition to Public Schools in West Virginia}

$\mathrm{I}$, , have been ask to allow my

child(ren),

to participate in this research study which has been

explained to me by Anne M. Krout. This research is being conducted to fulfill the requirements for a doctoral dissertation in Advanced Leadership Studies at West Virginia University.

The purpose of this study is to learn move about home schoolers transition to public schools in West Virginia.

This study involves a series of interviews and will take approximately two hours for me to complete. Approximately 16 subjects will be entered in this study. The interviews will be audio taped.

There are no known or expected risks from participating in this study.

I understand that this study is not expected to be of direct benefit to my child(ren), but the knowledge gained may be of benefit to others. My child will be given the financial remuneration of a $\$ 100.00$ savings bond.

For more information about this research, I can contact Dr. Phyllis Durden, Anne Krout's advisor, at West Virginia University by calling (304) 293-3707 at extension 1424. For information regarding my child(ren)'s rights as a research subject, I may contact the Executive Secretary of the Institutional Review Board at (304) 293-7073. 
I understand that any information about me obtained as a result of my child(ren)'s participation in this research will be kept as confidential as legally possible. I understand also that research records, just like hospital records, may be subpoenaed by a court order or may be inspected by federal regulatory authorities. In any publications that result from this research neither my child(ren)'s or my name nor any information from which I or my child(ren) might be identified will be published without my consent. The audiotapes used in recording the interviews will be kept in a locked storage area throughout the study. When the study has been completed, the audiotapes will be destroyed.

Participation in this study is voluntary. I understand that I am free to withdraw my child(ren) from this study at any time. Refusal to participate or withdrawal will involve no penalty or loss of benefits for me or my child. I have been given the opportunity to ask questions about the research, and I have received answers concerning areas I did not understand.

Upon signing this form, I will receive a copy.

I willingly consent to participate in this research.

Signature of Subject or Subject's Representative

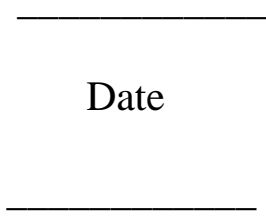

Date

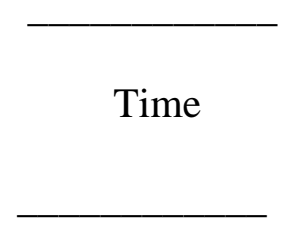

Time 


\section{Appendix L}

Teacher Consent and Information Form

\section{Home Schoolers' Transition to Public Schools in West Virginia}

I, have been invited to participate in this research study

which has been explained to me by Anne M. Krout. This research is being conducted to fulfill the requirements for a doctoral dissertation in Advanced Leadership Studies at West Virginia University.

The purpose of this study is to learn move about home schoolers transition to public schools in West Virginia.

This study involves a series of interviews and will take approximately two hours for me to complete. Approximately 16 subjects will be entered in this study. The interviews will be audio taped.

There are no known or expected risks from participating in this study.

I understand that this study is not expected to be of direct benefit to me, but the knowledge gained may be of benefit to others.

For more information about this research, I can contact Dr. Phyllis Durden, Anne Krout's advisor, at West Virginia University by calling (304) 293-3707 at extension 1424. For information regarding my rights as a research subject, I may contact the Executive Secretary of the Institutional Review Board at (304) 293-7073.

I understand that any information about me obtained as a result of my participation in this research will be kept as confidential as legally possible. I understand also that my research records, just like hospital records, may be subpoenaed by a court order or may be inspected by federal regulatory authorities. In any publications that result 
from this research neither my name nor any information from which I might be identified will be published without my consent. The audiotapes used in recording the interviews will be kept in a locked storage area throughout the study. When the study has been completed, the audiotapes will be destroyed.

Participation in this study is voluntary. I understand that I am free to withdraw my consent to participate in this study at any time. Refusal to participate or withdrawal will involve no penalty or loss of benefits. I have been given the opportunity to ask questions about the research, and I have received answers concerning areas I did not understand.

Upon signing this form, I will receive a copy.

I willingly consent to participate in this research.

Signature of Subject or Subject's Representative

Date

Time

Signature of Investigator

Date

Time 


\section{Parent Interview Guide I}

Introduction: I want to thank you for allowing me to visit with you today. I am interested in finding out ways that home schooling parents who choose to (re)enter their child in public school believe that public school can interface and assist families in making that transition. I would like to tape the interview so that I may have an accurate record of your responses when I begin the analysis of the data I collect. In no case will your name be identified nor will your comments be identified as yours. I would like for you to respond as fully as you can, although, if there are questions that you are not comfortable with answering, please let me know. If you need clarification of a question, please ask me for further explanation.

1) Bio questions: Where are you from? How many children do you have? What are your educational experiences?

2) Who initiated the return to public school? How was the decision made; factors considered?

3) What led you return your child to public school?

Prompts:

A) What did your child already know about public school? Probe as to what degree it was the parents' choice to the child's choice to go to public school? B) Did you or your child want to see how they compared to public school students?

C) Did your child want to participate in a certain part of the curriculum, 
such as, band, art, computers, sports, so they returned to school?

D) Did you want your child to have or your child want additional socialization that school may provide?

E) Was there a portion of the curriculum that you did not feel qualified to teach, such as advanced math, thus you returned your child to school?

F) Are there any other reasons you or your child wanted to return to public school?

4) How did you approach the school once you made the decision to return your child to school?

5) What was your reception by the school personnel like?

6) How did you arrive at a decision about what grade in which to place your child?

7) Describe the transition for your child? What went well? What were the problems?

8) What has been your relationship with the school been like? Your involvement?

9) How has your relationship with the faculty developed?

10) How has communication been with your child's teacher?

11) How did you learn of general information about the school? What did you learn from these persons?

12) What has the transition for your child been like?

Prompts:

(A) Treatment by teachers; by peers?

(B) Child's reaction?

(C) Adjustments to structure/organization of school?

(D) Academic progress/work? 
(E) Do you feel that you child is safe at school?

(F) Has you child had any problems with discipline at school? Following the rules?

(G) What could the school (principal and/or teachers) have done to make the transition to public school easier for your child? How could they have supported you and your child more?

13) What did you learn that could make the transition better?

14) How has your child felt about school since the transition?

15) How have you felt about this year?

16) Are there any points that we haven't discussed that are important?

17) Was there any portion of the curriculum in which your child felt like they were they were ahead in? Behind in?

18) Is there anything you would like to add that we have not discussed? May I contact you later if I have any further questions or need to clarify anything we have discussed today? 


\section{Appendix N}

\section{Parent Interview Guide II}

1. The parents interviewed felt that attending public school part time and home school part time would be a good idea and would be helpful to the transition back to public school full time. What are some examples that have led you to believe that part time attendance might be helpful? What kinds of issues might be attended to in the transition?

2. In the first interview, many parents felt that home schooled students needed emotional support and understanding when they first returned to public school. What are examples of events and issues that have led to this conclusion?

3. Some of the parents mentioned that more communication between families and boards of education throughout the home schooling experience is needed. What would be the critical issues for communications? What are some examples from the past that suggest communication has been a problem? What kinds of information exchange needs to take place during this time?

4. All parents interviewed suggested that meeting with teachers before the home schooled students returned to public schools would be beneficial. What would be shared during these meetings? What would need to be accomplished at these meetings?

5. Describe you child(ren)'s academic progress since the last time we spoke.

6. Describe you child(ren)'s socialization since the last time we talked.

7. Describe your child(ren)'s work load since the last time we talked. Describe the amount of subject matter covered. 
8. Are there any questions that we haven't talked about that you feel are important. 


\section{Appendix O}

\section{Student Interview Guide I}

Review Consent Agreement and sign.

1) Have you enjoyed your school year?

2) Whose idea was it for you to go to public school?

3) Why was it decided for you to go to public school?

4) What was it like going back to public school?

5) What was the work like in public school? Was it harder? Easier?

6) Is your teacher(s) helpful to you?

7) Did your teacher give you any special help because you were new at the school?

8) Have you made friends?

9) Did any of the other children ask you about being home schooled?

10) Do you feel safe at school?

11) Is there anything that you would like to talk about that we haven't discussed? 


\section{Appendix P}

\section{Student Interview Guide II}

1. Several students mentioned attending school on a part time basis as an option. How would you feel about attending part time as a way to ease back into public school?

2. What kinds of things would be addressed by attending school part time?

3. Students mentioned that more support was needed from teachers when they first returned to public school. What are examples of events that made you think that more support form teachers was needed?

4. Do you feel that it would have been beneficial to meet with your teacher(s) before starting classes?

5. What kinds of things should be addressed at a meeting with the teacher(s) before returning to school?

6. What are examples of extra materials that would have been helpful in your transition back to public schools? (Jessica only)

7. All the students I have interviewed mentioned that they wanted to return to school to be with friends or for social reasons. Please describe the process of going back to school and getting reacquainted friends or meeting new friends.

8. Describe your relationship with your teachers.

Prompts:

Have they been helpful to you when you needed assistance academically?

Do you feel like you could talk to them about a problem?

Have you ever approached them with a problem? What kind of problem?

9. How do you feel about your academic progress this year? 
10. Are there any questions that we haven't talked about that you feel are important? 


\section{Appendix Q}

\section{Teacher Interview Guide I}

Review Consent Agreement and sign.

1) Bio question

2) How were you notified that would be your student?

3) What was your first contact with the family; the student?

4) What were ;your early experiences like?

5) What were your initial feelings about having a home schooled student in your classroom?

6) Explain the student's transition experiences.

Prompts:

(A) Regarding discipline;

(B) socialization;

(C) academics;

(D) following rules; and

(E) following directions.

7) How was the student academically? in the area of technology?

8) How did the student's behavior/attitude compare to others?

9) How did you deal with his/her prior home school experiences?

10) What are your feelings in general regarding parents who home school their children? 


\section{Appendix R}

\section{Teacher Interview Guide II}

1. Many of the teachers interviewed indicated that they were not formally told from the school administration about having a returning home schooled student in their classroom. What would the impact of knowing before hand that you were going to have a returning home schooled student in you classroom? What kinds of information could have been shared before the student was assigned to your classroom?

2. Many parents interviewed said that they thought it would be beneficial to meet with the teacher before the returning child entered the classroom. What would the impact be of meeting with the student and parent before the student returns. What kinds of information would you like to learn form the parent or student?

3. Many of the parents interviewed felt that home schooled students needed emotional support and understanding when they returned to school. What have you observed that might lead you to believe that returning home schooled students to public schools need this kind of support?

4. Are there any additional ways in which a smoother transition could be accomplished for teachers, returning home schooled students and parents of returning home schooled students?

5. Are there any questions that we haven't talked about that you feel are important? 